\title{
Liquid and solution treatment by thermal plasma: a review
}

\author{
S. Safa $\cdot$ G. Soucy
}

Received: 29 October 2012/Revised: 15 May 2013/ Accepted: 22 July 2013/Published online: 13 August 2013

(C) Islamic Azad University (IAU) 2013

\begin{abstract}
During two last decades, numerous technologies and approaches are presented for treating contaminants in liquids and solutions. Among them, thermal plasma has shown rapid kinetic and high destruction efficiencies due to very high temperature and highly active radicals. Hence, the use of thermal plasma for treatment of the contaminants in liquids and solutions has received a lot of attention in view of its low environmental impacts. This review focuses on thermal plasma, and it describes the current status of liquid and solution treatment using this technology. A comprehensive analysis of the available scientific and technical literature on liquid and solution plasma treatment is presented, including the treatment of a variety of contaminants in liquids and solutions via different kinds of thermal plasma. The principles of thermal plasma generation and the available plasma technologies with potential applications to generate valuable products from liquid waste are presented. In addition, the results of the thermal plasma processes for the treatment of specific contaminants are investigated. In light of the investigated literature, thermal plasma is found to have a significant potential to treat the liquid wastes.
\end{abstract}

Keywords Environment $\cdot$ Liquid waste Thermal plasma technology . Waste treatment

S. Safa · G. Soucy $(\bowtie)$

Department of Chemical Engineering and Biotechnological

Engineering, Université de Sherbrooke, Sherbrooke J1K 2R1,

Canada

e-mail: Gervais.Soucy@USherbrooke.ca

\section{Introduction}

In the last 50 years, environmental pollution has become a global problem due to the significant increase in amount of waste. A huge amount of contamination is produced from industrial processes (Malik et al. 2002). The release of these contaminants in the environment from wastewater effluents can have potential health effects on humans and may also affect aquatic organisms in an unpredictable way (Magureanu et al. 2010; Malakootian et al. 2011). Moreover, the presence of a significant amount of organic contaminants in aqueous solution causes many difficulties in some industries such as pulp and paper and aluminum industry (Yargeau et al. 2001; Onundi et al. 2011). Therefore, liquid and solution treatments have become an important issue. Many efforts have been done to find effective methods for liquids treatment. Ability of treating a variety of waste types, off-gas, and residues composition as well as removal efficiency should be considered for choosing the appropriate destruction technique. Environmental friendly procedure is also an important factor for treatment processes. Polluting environment by by-product such as ozone depleting gas, greenhouse effect gases, or dioxins is also a serious issue for the treatment techniques.

Several techniques have been proposed for treating contaminants in liquid such as incineration and different types of plasma (Tomizawa and Tezuka 2006; Deegan et al. 2011). Due to combustibility of many types of waste, incineration has been used for reduction of waste. However, incineration suffers from various disadvantages including ash products, generation and release of $\mathrm{NO}_{x}$ and dioxin, high off-gas flow rates, need for cleaning off-gas, hazardous residues, and disposal obligation. Combustion process requires large air/fuel ratio for decomposition of contaminants. For treating wastes with a low heating value, 
additional source of fuel is required. Moreover, in the case of non-combustible wastes, even high-temperature incineration is not effective. Incineration is only able to volatilize these waste materials into gaseous phase and release unconverted toxins to the atmosphere. Also, landfills only transfer these pollutants from one phase to another. Accordingly, liquid waste especially liquid hazardous wastes, such as PCBs, paint solvents, and cleaning agents, are rapidly becoming an environmental threat due to their persistence and inertness. For such kinds of wastes, thermal plasmas can be a good treatment option. Moreover, it offers distinctive advantages including high enthalpy to enhance reaction kinetic, high chemical reactivity, oxidation and reduction atmosphere, and rapid quenching rate which lead to (Murphy 1999):

- High-volume reduction in most case

- A minimum volume of gaseous products requiring cleanup

- Low exhaust gas flow rates

- Low requiring gas flow

- Fast start-up and shut down

- Small reactor

- Portability allowing onsite destruction

Therefore, plasma treatment can be used for treating waste where either landfill is difficult, destruction with incineration requires treatment of the off-gas, or emission standard is stringent.

The large number of research articles published during the two last decades on treating contaminants in liquid and solution by plasma emphasizes the increasing interest in this particular application of plasma. This work will briefly review different types of thermal plasma and will summarize current status of research on liquid treatment via different kinds of thermal plasma. Available scientific and technical literatures will be analyzed, and the results of thermal plasma treatment of some specific contaminants will be presented. This review was performed during 2011-2012 at Department of Chemical Engineering and Biotechnological Engineering, Université de Sherbrooke, Canada.

\section{Plasma}

In 1879, Sir William Crookes identified Plasma for the first time in a Crookes tube, and he called it "radiant matter," and the latter was modified to "plasma" in 1928 by Langmuir (1928).

Plasma is considered to be the fourth state of matter. It contains a mixture of electrons, ions, and neutral particles. In plasma technology, an electrical current or electromagnetic field passing through the gas will generate the plasma. When sufficient number of charge carriers (such as electrons) is generated, the electrical breakdown of the gas occurs. The collision between the generated electrons and gas molecules can lead to the formation of ions, excited species, atoms, and photons (Boulos et al. 1994). In this state, high concentration of free electrons causes plasma to become highly electrically conductive (Moustakas et al. 2005). A number of gases can be used for the plasma including argon, hydrogen, helium, nitrogen, oxygen, air, steam, $\mathrm{CO}$, and $\mathrm{CO}_{2}$. The availability and contribution to desired chemical reactions are the characteristics for selection of plasma gas. Argon and $\mathrm{N}_{2}$ are normally used for plasma generation. In processes which oxidation is required, oxygen can be used as a plasma gas (Mabrouk et al. 2012).

Plasma is classified by pressure, temperature, and electron densities. There are two main types of plasmas: atmospheric pressure and low pressure (Kong 2006). Atmospheric pressure plasmas are divided in two main groups: thermal plasma and non-thermal plasma. In non-thermal plasma, $T_{\mathrm{e}} \gg T_{h} \sim$ $300-400 \mathrm{~K}$ and $n_{\mathrm{e}} \sim 10^{10} \mathrm{~m}^{-3}\left(T_{\mathrm{e}}=\right.$ electron temperature; $T_{h}=$ neutral particle temperature; $n_{\mathrm{e}}=$ Electron density). However, in thermal plasma, $T_{\mathrm{e}} \sim T_{h}=2,000-30,000 \mathrm{~K}$ and $n_{e} \geq 10^{20} \mathrm{~m}^{-3}$. Therefore, thermal plasmas are characterized by a high-energy density and the identical temperature of heavy particles and electrons (Gomez et al. 2009).

In the following, the characteristics of thermal plasma will be elaborated in more details.

\section{Classification of thermal plasma}

Thermal plasma has shown unique advantages for treating aqueous solutions. It has both high-energy density and temperature which lead to fast reaction, high heat flux which allow rapid start-up and shut down times and rapid quenching to produce non-equilibrium chemical compositions. It provides the possibility of a large throughput in small reactor. Moreover, it can provide oxidation and reduction atmospheres in accordance with required chemical reactions and the ability to destroy any kind of chemical bonds (Heberlein and Murphy 2008; Narengerile et al. 2011). Due to these advantages, it is not surprising that thermal plasma has been proposed as a green technology for treating aqueous solution during the past several years.

Thermal plasma can be produced by (Murphy 1999):

1. Direct current (DC) or alternating current (AC) electrical arc torch

2. Radio frequency induction (RF)

3. Microwave discharge plasma (MW)

Among these, DC arc plasma and radio frequency have been mostly applied for aqueous solutions treatment. In the following sections, all these technologies will be discussed. 
Effectiveness of thermal plasma technology for waste treatment

Effectiveness of waste treatment by thermal plasma can be evaluated by different factors such as destruction and removal efficiency (DRE), and the composition of byproduct and emission level of undesirable environmental products like dioxins, furans, etc. Process efficiency shows the ability of a technology to destroy wastes in a consistent way with environmental regulations. Destruction is typically evaluated by using a concept which initially was established under the Resource Conservation and Recovery Act (RCRA), known as destruction and removal efficiency (DRE). DRE is defined as the difference between the amount of chemicals going into a process and the amount that is sent out to atmosphere after off-gas treatment. For most organic components, the RCRA regulations require a DRE of $99.99 \%$ (otherwise known as four nines). However, for some component groups, such as dioxins and furans, a DRE of $99.9999 \%$ (six nines) is required. However, the DRE of $99.9999 \%$ has become an informal basis for comparison of chemical agent destruction processes.

The emission limits of environmental undesirable products vary for different applications in different parts of the world and for different industries. These limits evaluate technologies from an environmental point of view. Also, they show the ability of treatment technology for destruction of hard to destroy wastes like dioxins. Emission limit of some of hazardous components and incineration products according to CCME (Canadian Council of Ministers of Environment 1992) specified by various justifications is presented in Tables 1 and 2 (Chandler and Associates Ltd. 2006). These limits, originally established for incineration processes, can also be used to evaluate plasma technology:

According to above data, the dioxins and furans numeric targets in the CWS are more stringent than those in the other part of the world. Using the above data, the emission levels of hazardous waste below the incineration limits will be used for specifying effectiveness of thermal plasma technology for waste treatment.

\section{Results and discussion}

DC plasma torch for treating contaminants in liquid and solutions

DC arc discharge presents high-energy density and high temperature between two electrodes (Huang and Tang 2007). Most DC arc torches have three main components including cathode, plasma-forming gas injection stage, and anode. Arc torches and electrodes are usually water-cooled. Plasma, in the form of high enthalpy jet, can be produced above one of the electrodes.

The arc generated plasma can be divided in three categories:

1. Transferred arc (Fig. 1a). One of the electrodes can be the treated material and is placed in an electrically grounded metallic vessel. Therefore, an electrical conductive material should be chosen as reacting material.

2. Non-transferred arc (Fig. 1b). There are two electrodes in this plasma which do not participate in the processing and have the sole function of plasma generation (Huang and Tang 2007).

3. Twin torch. It contains two torches. One of the torches serves as the anode and other serves as the cathode. This kind of torch can either work in transferred mode or non-transferred mode (Heberlein and Murphy 2008).

Among these three kinds of torch, transferred arc plasma generates high temperature. But, it has the disadvantage of not being able to treat non-conducting materials. The twin arc can operate in transferred and non-transferred mode. It

Table 1 International incinerator dioxins and furans emission regulations [pg I-TEQ/Rm $\left.{ }^{3} @ 11 \% \mathrm{O}_{2}\right]$

\begin{tabular}{llll}
\hline Country & Incinerator type & Emission limit & Comments \\
\hline EU (European Union) & All & 92 & - \\
CWS (Canada Wide Standards) & All & $80\left(0.08 \mathrm{ng} / \mathrm{Rm}^{3}\right)$ & $\begin{array}{c}\text { All new construction after 2001, } \\
\text { existing facilities limited to } 100 \mathrm{pg} \text { ITEQ/Rm }\end{array}$ \\
United States (EPA) & Hazardous waste & 140 & - \\
Australian and New Zealand & All & 92 & - \\
Japan & & $92-4,600$ & Existing facilities have limit of $920-9,200$
\end{tabular}

$\mathrm{Rm}^{3}=$ dry Reference cubic meter (at $25^{\circ} \mathrm{C}, 101.3 \mathrm{kPa}$ and $11 \% \mathrm{O}_{2}$ ), TEQ = toxic equivalent quantity, I-TEQ/Rm ${ }^{3}=$ international toxicity equivalents (the toxicity equivalence factors recommended by the North Atlantic Treaty Organizations's Committee on Challenges to Modern Society (NATO/CCMS) in 1989 and adopted by Canada in 1990) to 2,3,7,8 tetrachlorodibenzo- $p$-dioxin per reference cubic meter at $25{ }^{\circ} \mathrm{C}$ and $101.3 \mathrm{kPa}$ pressure. Concentrations are corrected to $11 \%$ oxygen and zero percent moisture (dry) 
Table 2 Hazardous waste incineration emission limits, acid gases, and combustion products specified by various justifications (values expressed as mg/Rm ${ }^{3} @ 11 \% \mathrm{O}_{2}$ ) (CCME 1992)

\begin{tabular}{llll}
\hline Contaminant & $\begin{array}{l}\text { CWS (Canada } \\
\text { Wide Standard) }\end{array}$ & $\begin{array}{l}\text { United States } \\
\text { (EPA) }\end{array}$ & Japan \\
\hline Particulate matter & 50 & 128 & 153 \\
Hydrogen chloride (HCl) & 75 & $99 \%$ & 712 \\
\hline
\end{tabular}

works as transferred arc when the current flow goes from one electrode to the charge and from the charge to the other torch. Also, it can work in non-transferred arc mode when the current goes form one electrode directly to another electrode. The twin torch generates high temperature and also can treat non-conducting materials like medical waste due to its high-temperature arc column. However, control of its arc mode is not easy, and it has lower heating efficiency compared to single torch (Iwao et al. 2005).

Non-transferred arc can treat non-conducting materials and offers simpler mechanical control requirements compared to transfer-type torches. Moreover, it provides great bulk gas heating capability, high arc stability, especially during the heat-up period, simple reactor design, and great overall system reliability (Capote et al. 2007). A non-transferred type torch can be used for treating waste with high organic concentration. Non-transferred arc processes are chosen for treatment of liquids due to having more uniform temperature distribution and the availability of reactive species.

Researchers began using plasma arc as a technology that could be used to destroy industrial wastes in 1980 . The objective was to reach effective degradation with high removal efficiency, low by-product formation, and low energy consumption. Also, such unit should be operated with minimum investment and minimum interface with industrial efficiency and output. An overview of these research activities since early 1990s is given in Table 3 .

The location and process of feed introduction are quite important for having effective interaction and well mixing between plasma jet and solution. The above technologies use two overall different methods for making the interaction between plasma and solution feed:

1. Solution injection into the plasma jet

2. Plasma jet injection into volume of solution (submerged plasma)

These two injection methods will lead to different energy efficiency. Another important factor in thermal plasma technology is the plasma gas. Air, $\mathrm{O}_{2}$, argon, and nitrogen are mostly used as plasma gas in these two injection methods. However, steam is only used as plasma gas in the solution injection into plasma jet. These gases have different plasma enthalpies, which lead to different materials processing rates. In the following sections, the above-mentioned literature (Table 3 ) is discussed in more details.

\section{Liquid injection into plasma jet}

One of the reasons for considering plasma processing is the ability to process a varied mixture with relatively low gas throughput (Donaldson et al. 1991). Moreover, effective degradation with high removal efficiency and low byproduct formation in liquid treatment is an important factor specially for treating hazardous or radioactive wastes. Knak et al. (1997) conclude that the destruction results can be improved by good mixing of the plasma with the treatment solution. They use an electrical arc plasma
Fig. 1 Method of generating DC thermal plasma torch): a transferred arc; b nontransferred arc (Murphy 1999)
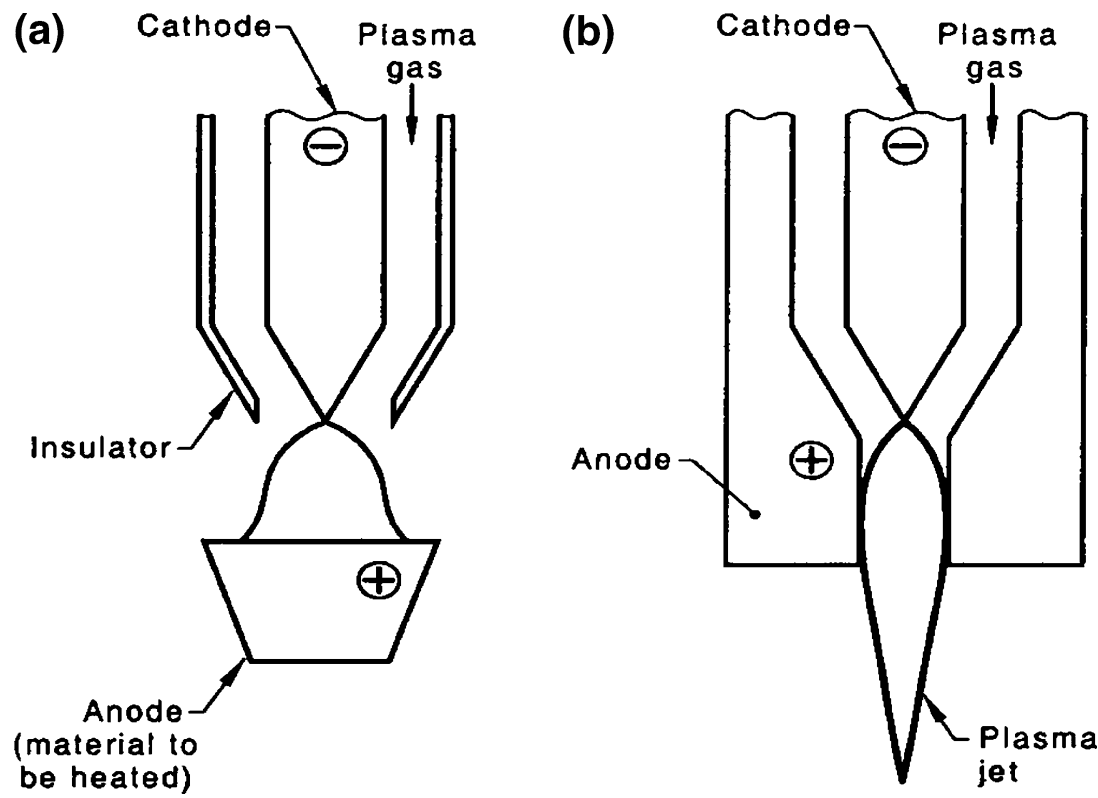
Table 3 Recent experimental works on arc plasma liquid and solution treatment

Type of plasma, type of liquid and Type of reactor, condition, and treatment results $\quad$ References
treatment reaction

Liquid injection into the plasma jet

Electrical arc plasma, laboratory scale, real hazardous liquid

DC plasma torch, laboratory scale, test liquid, pyrolysis of organic

Non-transferred AC plasma, torch laboratory scale, test liquid, thermal oxidation

DC non-transferred plasma arc, laboratory scale, test liquid, photochemical dissociation
Reactor: plasma unit with a straight-through reactor

Knak et al. (1997)

Plasma torch power: $5-17 \mathrm{~kW}$

Plasma gas: air, steam

Plasma gas flow rate: air: $0.7-1.6 \mathrm{~m}^{3} / \mathrm{h}$ or steam: $1.5-2.0 \mathrm{~kg} / \mathrm{h}$

Waste feeding rate: $0.2-1.8 \mathrm{~kg} / \mathrm{h}$

liquid sample: mixture containing cyclohexane

Destruction and removal efficiency: n/a (not available)

Energy consumption: $9.4 \mathrm{kWh} / \mathrm{kg}$ (for $1.8 \mathrm{~kg} / \mathrm{h}$ feeding rate and $17 \mathrm{~kW}$ plasma power)

Destruction and removal result: chlorine-containing compounds in exhaust gases does not exceed $0.5 \mathrm{ng} / \mathrm{m}^{3 \mathrm{a}}$

Reactor: tube reactor with counter-flow liquid injection plasma

Plasma torch power: $40 \mathrm{~V} \times 500 \mathrm{~A}=20 \mathrm{~kW}$

Sample time: $1 \mathrm{~h}$

Plasma gas: air

Plasma gas flow rate: $1,440 \mathrm{~m}^{3} / \mathrm{h}$

Atomizing gas flow rate $\left(\mathrm{O}_{2}\right): 720 \mathrm{~m}^{3} / \mathrm{h}$

Waste feeding rate: $52 \mathrm{~kg} / \mathrm{h}$

Liquid sample: benzene and carbon tetrachloride, which were used as stimulants of PCBs

Destruction and removal efficiency (DRE): $99.99986 \%$

Energy consumption: $0.38 \mathrm{kWh} / \mathrm{m}^{3}$

Reactor: a commercial arc welding supply is used to power the plasma torch in a cylinder reactor

Plasma gas: argon with addition oxygen

Liquid sample: acetone

Waste feeding rate: $0-158 \mathrm{~kg} / \mathrm{h}$

Energy consumption: n/a

Optimizing parameters for increasing destruction efficiency are:

Increasing the current $>50 \mathrm{~A}$; Argon flow rates should be less than $1.1 \mathrm{Nm}^{3} / \mathrm{h}$; Oxygen injection (DE $>99 \%)$

Plasma torch power: $1.5 \mathrm{~kW}$

Plasma gas: Argon

Snyder and Fleddermann (1997)
Han et al. (1993)

Snyder et al. (1996)

Plasma gas flow rate: $1,050 \mathrm{~m}^{3} / \mathrm{h}$

Waste feeding rate: $150 \mathrm{~kg} / \mathrm{h}$

Liquid sample: liquid 1,2-dichloroethane as a hazardous liquid

Destruction and removal efficiency: n/a

Conversion: 0.98 at injecting point $(10 \mathrm{~mm}$ the center axis of the plasma jet)

Energy consumption: $12.5 \mathrm{kWh} / \mathrm{m}^{3}$ 
Table 3 continued

\begin{tabular}{l}
\hline $\begin{array}{l}\text { Type of plasma, type of } \\
\text { liquid and treatment } \\
\text { reaction }\end{array}$ \\
\hline
\end{tabular}

\begin{tabular}{|c|c|c|}
\hline $\begin{array}{l}\text { Three electrical arc plasma, } \\
\text { laboratory scale, real } \\
\text { hazardous liquid, } \\
\text { oxidation (high } \\
\text { temperature combustion) }\end{array}$ & $\begin{array}{l}\text { Plasma reactor with three-jet mixing chamber } \\
\text { Plasma torch power: } 28-40 \mathrm{~kW} \\
\text { Plasma gas: air } \\
\text { Plasma gas flow rate: } 22.5-31.7 \mathrm{~kg} / \mathrm{h} \\
\text { Waste feeding rate: } 3.6 \mathrm{~kg} / \mathrm{h} \\
\text { liquid sample: chlorine-containing waste (aqueous solution) } \\
\text { Energy consumption: } 11.1 \mathrm{kWh} / \mathrm{kg} \text { (at } 40 \mathrm{~kW} \text { plasma power) } \\
\text { Result: gases phase sample chlorine in pure form is not } \\
\text { detected } \\
\text { Plasma torch power: } 94-120(82-108) \mathrm{kW} \\
\text { Plasma gas flow rate: } 16.9-21.6 \mathrm{~kg} / \mathrm{h} \\
\text { Waste feeding rate: } 1-15.5(5.6-12.5) \times 10^{-3} \mathrm{~kg} / \mathrm{h} \\
\text { Liquid sample: } 25 \% \text { concentration of bromine phenols } \\
\text { containing waste in aqueous solution (and } 75 \% \text { solution } \\
\text { waste in a polar organic solvent) } \\
\text { Destruction and removal efficiency: } \mathrm{n} / \mathrm{a} \\
\text { Energy consumption: } 8.64 \times 10^{3} \mathrm{kWh} / \mathrm{kg} \text { (plasma power } \\
108 \mathrm{~kW} \text { and } 12.5 \mathrm{~g} / \mathrm{h}) \\
\text { Result: toxic dioxin and carbon monoxide were not detected }\end{array}$ & Knak et al. (1997) \\
\hline $\begin{array}{l}\text { Non-transferred arc plasma } \\
\text { torch, industrial-relevant } \\
\text { scale, real hazardous } \\
\text { liquid }\end{array}$ & $\begin{array}{l}\text { Plasma reactor: PLASCON }{ }^{\mathrm{TM}} \text { system } \\
\text { Plasma torch power: } 150 \mathrm{~kW} \\
\text { Plasma gas: argon } \\
\text { Liquid sample: organic liquid containing dichlorophenols, } \\
\text { dioxin, and other organic species. } \\
\text { Destruction and removal efficiency: } 99.9999 \% \\
\text { Energy consumption: } \mathrm{n} / \mathrm{a} \\
\text { Dioxin and furan emission: less than } 0.01 \mathrm{ng} \mathrm{m}^{-3} \text { toxic } \\
\text { equivalent }\end{array}$ & Murphy (1999) \\
\hline $\begin{array}{l}\mathrm{DC} \text { cascade plasma torch, } \\
\text { laboratory scale, test } \\
\text { liquid }\end{array}$ & $\begin{array}{l}\text { Plasma torch power: } 1-5 \mathrm{~kW} \\
\text { Waste Feeding rate: } 0.015-0.35 \mathrm{~kg} / \mathrm{h} \\
\text { liquid sample: hydrocarbon solution } \\
\text { Destruction and removal efficiency (DRE): } \mathrm{n} / \mathrm{a} \\
\text { Energy consumption: } 14.4 \mathrm{kWh} / \mathrm{kg} \text { (for } 0.35 \mathrm{~kg} / \mathrm{h} \text { ) }\end{array}$ & Pacheco et al. (2001) \\
\hline Steam DC plasma & & \\
\hline $\begin{array}{l}\text { DC non-transferred steam } \\
\left(\mathrm{H}_{2} \mathrm{O}\right) \text { plasma, real } \\
\text { hazardous liquid, } \\
\text { gasification }\end{array}$ & $\begin{array}{l}\text { Plasma reactor: Steam plasma (circular reactor of vertical type) } \\
\text { Plasma torch power: } 100 \mathrm{~kW} \\
\text { Plasma gas: steam } \\
\text { Plasma gas flow rate: } 9.4-10.1 \mathrm{~kg} / \mathrm{h} \\
\text { Sample feeding rate: } 68.4 \mathrm{~kg} / \mathrm{h} \\
\text { Liquid sample: the treatment of liquid hazardous waste such as } \\
\text { PCBs, chlorinated solvent wastes, pesticide wastes, and so on } \\
\text { [PCB is a mixture of } 57 \% \text { trichlorobiphenyl }\left(\mathrm{C}_{12} \mathrm{H}_{7} \mathrm{Cl}_{3}\right) \text { and } \\
\left.43 \% \text { tetrachlorobiphenyl }\left(\mathrm{C}_{12} \mathrm{H}_{6} \mathrm{Cl}_{4}\right)\right] \\
\text { Destruction and removal efficiency }(\mathrm{DRE}): 99.9999 \% \\
\text { Energy consumption: } 1.5 \mathrm{kWh} / \mathrm{kg} \\
\text { Dioxin and furan emission: } 0.056 \mathrm{ng} \mathrm{m}{ }^{-3} \text { toxic equivalent }\end{array}$ & Seok-Wan et al. (2003) \\
\hline
\end{tabular}


Table 3 continued

Type of plasma, type of liquid and treatment reaction
DC non-transferred arc plasma torch (DC water plasma), laboratory scale, test liquid, pyrolysis and combustion, chemical oxidation or reduction
Type of reactor, condition, and treatment results

References

Plasma reactor: Water-soluble organic compounds pass through the discharge region of the water plasma

Plasma torch power: $0.91-1.05 \mathrm{~kW}$

Plasma gas: $100 \%$ steam and methanol and ethanol were mixed with water for plasma-supporting gas

Plasma gas flow rate: plasma gas flow rate increases with increasing alcohol concentration because of increasing vapor pressure. Higher vapor pressure of the methanol solution causes larger feed rate of the plasma-supporting gas evaporated from the methanol solution

liquid sample: Methanol or ethanol used as a model substance of water-soluble organic compounds

Destruction and removal efficiency (DRE): n/a

Energy consumption: n/a

Plasma reactor: DC water plasma

Plasma torch power: $0.91 \mathrm{~kW}$

Plasma gas: steam

Aqueous solution: aqueous phenol solution $\left(5.23 \times 10^{-3}\right.$ to $\left.52.8 \times 10^{-3} \mathrm{~kg} / \mathrm{m}^{3}\right)$

Feed rate of phenol: $5.76 \times 10^{-4}$ to $6.12 \times 10^{-3} \mathrm{~kg} / \mathrm{m}^{3}$

The removal efficiency of total organic carbon (TOC): $99.7 \%$

Destruction and removal efficiency (DRE): $99.68 \%$

Energy consumption: $0.58 \times 10^{6}$ to $5.26 \times 10^{6} \mathrm{kWh} / \mathrm{kg}$

Product: $\mathrm{CO}$ and $\mathrm{CO}_{2} \mathrm{CH}_{4}$ and $\mathrm{C}_{2} \mathrm{H}_{2}$

Plasma reactor: DC water plasma at atmospheric pressure

Plasma torch power: $1.08 \mathrm{~kW}$

Plasma gas: no chemicals additive

Liquid sample: high concentration of phenol solution $(1 \mathrm{~mol} \%)$

The phenol decomposition rate: $98.2-99.99 \%$ (at arc currents 6-8 A)

Destruction and removal efficiency: $99.9999 \%$

Energy consumption: n/a

Plasma reactor: DC water plasma at atmospheric pressure

Narengerile and Watanabe (2012)
Yuan et al. (2010)

Narengerile et al. (2011)

Plasma torch power: $0.66-0.91 \mathrm{~kW}$

Plasma gas: steam

Aqueous solution: aqueous acetone

Working pressure: atmospheric pressure

Destruction and removal efficiency: $99.8 \%$ (at an arc current of $7 \mathrm{~A}$ )

Energy efficiency: $1.7 \times 10^{-7} \mathrm{~mol} / \mathrm{J}$

Energy consumption: $28.1 \mathrm{kWh} / \mathrm{kg}$ 
Table 3 continued

\begin{tabular}{|c|c|c|}
\hline $\begin{array}{l}\text { Type of plasma, type of liquid } \\
\text { and treatment reaction }\end{array}$ & Type of reactor, condition, and treatment results & References \\
\hline $\begin{array}{l}\text { DC non-transferred arc plasma } \\
\text { torch (DC water plasma), } \\
\text { laboratory scale, test liquid }\end{array}$ & $\begin{array}{l}\text { Plasma reactor: water thermal plasma } \\
\text { Plasma torch power: less than } 1 \mathrm{~kW} \\
\text { Plasma gas: steam } \\
\text { Liquid sample: } 1 \text {-decanol emulsion, 1-butanol } \\
\text { Destruction and removal efficiency: } 99.9999 \% \\
\text { Energy consumption: } \mathrm{n} / \mathrm{a}\end{array}$ & Choi and Watanabe (2012) \\
\hline Plasma jet injection into volume & $\begin{array}{l}\text { quid (submerged plasma) } \\
\text { Plasma reactor: submerged plasma torch with internal recirculation by } \\
\text { draft tube } \\
\text { Plasma torch power: } 10-24 \mathrm{~kW} \\
\text { Plasma gas: argon (low power plasma) and } \mathrm{Ar} / \mathrm{N}_{2} \text { (high power) } \\
\text { Waste volume: } 20 \mathrm{~m}^{3} \\
\text { Liquid sample: free and complex cyanides in solution } \\
\text { Destruction and removal efficiency: } \mathrm{n} / \mathrm{a} \\
\text { Energy consumption: } 1 \mathrm{kWh} / \mathrm{m}^{3} \\
\text { Results: The higher rate of cyanide destruction are compared to } \\
\text { thermal hydrolysis occurring in a plug-flow reactor } \\
\text { Product: mostly } \mathrm{H}_{2} \mathrm{O} \text { and } \mathrm{CO}_{2}\end{array}$ & Fortin et al. (2000) \\
\hline \multirow[t]{3}{*}{$\begin{array}{l}\text { DC non-transferred plasma } \\
\text { torch, pilot plant, test liquid, } \\
\text { thermal hydrolysis }\end{array}$} & $\begin{array}{l}\text { Plasma reactor: submerged plasma reactor with internal recirculation } \\
\text { by draft tube } \\
\text { Plasma torch power: } 45 \mathrm{~kW} \\
\text { Plasma gas: air or } \mathrm{O}_{2} \\
\text { Waste Feed concentration: } 0.42 \mathrm{~mol} / \mathrm{m}^{3} \\
\text { Liquid sample: formic acid (black liquor lignin) } \\
\text { Treatment time: } 20 \mathrm{~min} \\
\text { Destruction and removal efficiency (DRE): } \mathrm{n} / \mathrm{a} \\
\text { Energy consumption: } \mathrm{n} / \mathrm{a}\end{array}$ & Yargeau et al. (2004) \\
\hline & $\begin{array}{l}\text { Plasma reactor: submerged plasma reactor with internal recirculation } \\
\text { by draft tube } \\
\text { Plasma torch power: } 100 \mathrm{~kW} \\
\text { Plasma gas: Air } \\
\text { Volume of liquid: } 15-20 \mathrm{~m}^{3} \\
\text { Waste Feed concentration: } 8.3 \times 10^{-3} \mathrm{~kg} / \mathrm{m}^{3} \text { (for six organic acid) } \\
\text { Liquid sample: synthetic Bayer liquor (contains six organic acid such } \\
\text { as: Salicylic acid, Mesaconic acid, Methysuccinic acid, Adipic acid, } \\
\text { Isophthalic acid, Lactic acid) } \\
\text { Treatment time: } 23 \text { min } \\
\text { Destruction and removal efficiency (DRE): } \mathrm{n} / \mathrm{a} \\
\text { Energy consumption: } 1.9 \mathrm{kWh} / \mathrm{m}^{3}\end{array}$ & Soucy et al. (2006) \\
\hline & $\begin{array}{l}\text { Plasma reactor: submerged plasma reactor with internal recirculation } \\
\text { by draft tube } \\
\text { Plasma torch power: } 40 \mathrm{~kW} \\
\text { Plasma gas: oxygen (air) } \\
\text { Plasma gas flow rate: } 1,358 \mathrm{~m}^{3} / \mathrm{h} \\
\text { Liquid sample: Bayer spent evaporated liquor } \\
\text { Treatment time: } 25 \text { min } \\
\text { Destruction and removal efficiency (DRE): } \mathrm{n} / \mathrm{a} \\
\text { Energy consumption: } \mathrm{n} / \mathrm{a}\end{array}$ & $\begin{array}{l}\text { Armstrong and Soucy } \\
\text { (2007) }\end{array}$ \\
\hline
\end{tabular}


Table 3 continued

\begin{tabular}{|c|c|c|}
\hline $\begin{array}{l}\text { Type of plasma, type of liquid and } \\
\text { treatment reaction }\end{array}$ & Type of reactor, condition, and treatment results & References \\
\hline $\begin{array}{l}\text { Non-transferred arc plasma torch, } \\
\text { laboratory scale, test liquid, } \\
\text { gasification }\end{array}$ & $\begin{array}{l}\text { Plasma reactor: submerged plasma reactor } \\
\text { Plasma torch power: } 4-30 \mathrm{~kW} \\
\text { Plasma gas: argon and oxygen (argon }+ \text { hydrogen) } \\
\text { Plasma gas flow rate: } 900 \mathrm{~m}^{3} / \mathrm{h} \text { argon and } 180 \mathrm{~m}^{3} / \mathrm{h} \\
\text { oxygen } \\
\text { Solution volume: } 15 \mathrm{~m}^{3} \\
\text { Aqueous solution: decontamination of solutions } \\
\text { contaminated by dye molecules (methylene blue) } \\
\text { and chlorinated molecules (chlorophenol). } \\
\text { Domestic sewage sluge and a steel industry } \\
\text { effluent } \\
\text { Treatment time: } 40 \text { min } \\
\text { Destruction and removal efficiency (DRE): } 45 \% \\
\text { Energy consumption: } 0.22 \mathrm{kWh} / \mathrm{m}^{3}\end{array}$ & Boudesocque et al. (200 \\
\hline $\begin{array}{l}\text { DC non-transferred arc plasma torch, } \\
\text { laboratory scale, test liquid, } \\
\text { oxidation }\end{array}$ & $\begin{array}{l}\text { Plasma reactor: under water thermal plasma } \\
\text { Plasma torch power: } 50 \mathrm{~kW} \\
\text { Plasma gas: oxygen } \\
\text { Plasma gas flow rate: } 108 \times 10^{2} \mathrm{Nm}^{3} / \mathrm{h} \text { (at the } \\
\text { anode) } \\
\text { Liquid sample: tributylphosphate (TBP)/dodecane, } \\
\text { Perfluoropolyether oil, Trichloroethylene (TCE) } \\
\text { Sample flow rate: } 0.004 \mathrm{~m}^{3} / \mathrm{h} \\
\text { Destruction and removal efficiency: better than } \\
99.97 \% \\
\text { Energy consumption: } \mathrm{n} / \mathrm{a} \\
\text { Torch efficiency: } 62 \%\end{array}$ & Mabrouk et al. (2012) \\
\hline $\begin{array}{l}\text { DC plasma torch, laboratory scale, test } \\
\text { liquid, high-speed oxidizing }\end{array}$ & $\begin{array}{l}\text { Plasma reactor: a reactor with a water-cooling jacket } \\
\text { Plasma torch power: } 20 \mathrm{~kW} \\
\text { Plasma gas: } \mathrm{O}_{2}-\mathrm{Ar} \text { mixture, }\left(\mathrm{O}_{2}-\mathrm{N}_{2}\right) \\
\text { Plasma gas flow rate: } 0.6-0.7 \mathrm{sm}^{3} / \mathrm{h} \\
\text { Aqueous solution: aqueous solutions of phenol and } \\
\text { humic acids } \\
\text { Waste concentration: } 15-750 \times 10^{-6} \mathrm{~kg} / \mathrm{m}^{3} \\
\text { Treatment time: } 8-45 \mathrm{~min} \\
\text { Destruction and removal efficiency: } 80 \% \\
\text { Energy consumption: } \mathrm{n} / \mathrm{a} \\
\text { Enthalpy of the plasma: } 1.2-2.9 \mathrm{kWh} / \mathrm{m}^{3} \\
\left(5-9.2 \mathrm{kWh} / \mathrm{m}^{3}\right)\end{array}$ & Samokhin et al. (2010) \\
\hline
\end{tabular}

a In 1988, a CCME predecessor issued a report concerning the anticipated performance of waste incinerators. Shortly thereafter, a similar
document related to hazardous waste incinerators was issued. While the initial report stopped short of defining a regulatory limit for emissions
from waste incinerators, based upon data available at the time, it suggested that well-operated facilities should be able to limit PCDD/F emissions to $0.5 \mathrm{ng} \mathrm{TEQ} / \mathrm{Rm}^{3} @ 11 \% \mathrm{O}_{2}$

generator with air or steam as plasma-forming gas to treat liquid toxic waste (a solution containing cyclohexane as a raw waste model). By increasing the contact between plasma and the solution, the chlorine-containing compounds in exhaust gases do not exceed $0.5 \mathrm{ng} / \mathrm{m}^{3}$, which is below the emission levels suggested by CCME at that time.

The location and method used for introducing liquid into the plasma reactor as well as long residence time have a direct effect on the well interaction between the solution and plasma (Han et al. 1993). The method suggested by Han et al. includes a laboratory scale counter-flow liquid injection which provides high relative velocities between the reactants and the plasma. Also, it leads to an intense mixing zone of two jets and long residence times for the liquid in the high temperature region. Carbon tetrachloride and benzene are used as simulate of PCBs. The destruction 


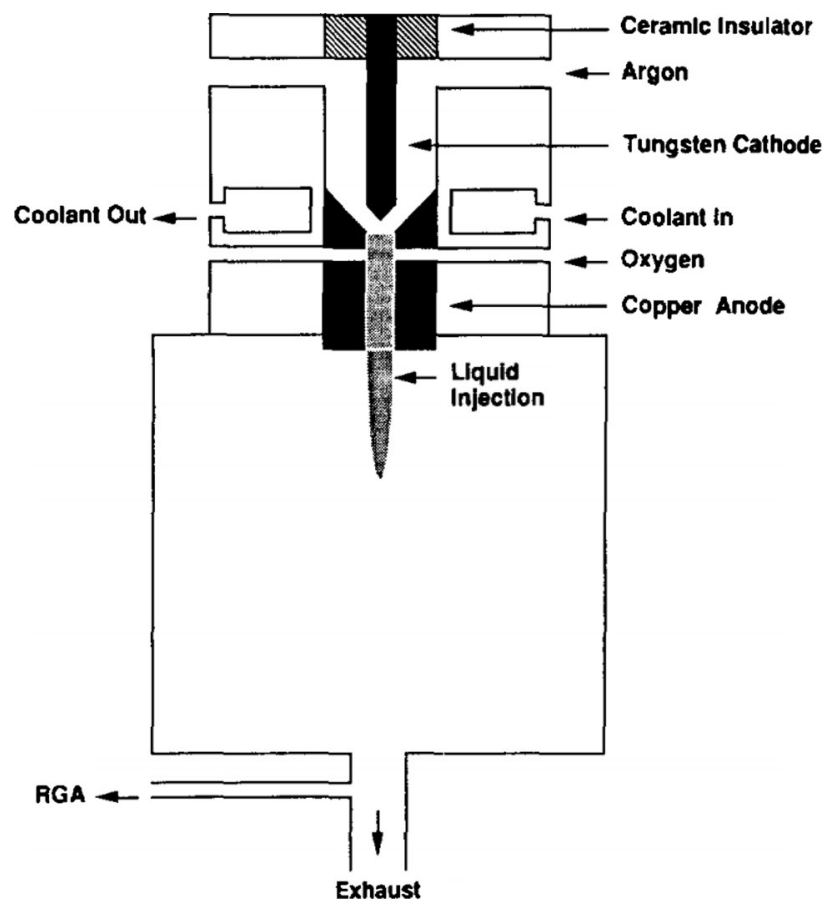

Fig. 2 Schematic diagram of the arc jet plasma reactor (Snyder et al. 1996)

and removal efficiencies (DRE) for benzene are greater than $99.99 \%$, which is under the RCRA limit for this waste. This condition offers a favorable operation environment for solution treatment. Moreover, the facility of mixing the reactants and the plasma gas and large residence time can be achieved by large recirculation inside the reactor.

For introducing the liquid into plasma jet, several methods are proposed and the effect of these methods is investigated on destruction efficiency. Snyder et al. (1996) investigated destruction of acetone as a hazardous waste which was introduced transversely to the plasma stream in a small-scale thermal non-transferred plasma torch as it can be seen in Fig. 2.

A copper nozzle is used as the anode, and a $0.31 \mathrm{~cm}$ diameter tungsten rod acts as the cathode. The metal cathode and anode are quickly damaged via oxidation reactions. Destruction efficiency is studied as a function of solvent flow rate, torch power, argon flow rate, and oxygen injection rate. The plasma parameters are optimized to reach maximum destruction efficiency. Destruction efficiency is increased by lowering the plasma gas flow (increasing the residence time) or increasing the arc jet current which leads to an increase in the temperature of plasma gas in a pyrolysis system (without adding oxygen). Using carrier gas (argon) can increase the destruction efficiency in thermal oxidation mode because it makes atomizing liquid and liquid droplets. This will lead to an acceleration of the heat transfer from the plasma to acetone due to higher amount of surface to volume ratio for the liquid droplets. Injection of oxidizing agent like oxygen at the point where liquid converts to droplets leads to complete mixing of the acetone and oxidizing agent and increases the removal efficiency. The same rate of removal is achieved with almost an order of magnitude less power by injecting additional oxygen to system. They achieved the destruction efficiency greater than $99 \%$ by using additional oxygen at the arc jet current of $75 \mathrm{~A}$, which is lower than the required DRE for this kind of waste under RCRA regulations (DRE of $99.99 \%$ ).

The critical parameters related to thermal plasma chemistry and the destruction of liquid waste were also investigated (Snyder and Fleddermann 1997). The multiple reaction mechanisms which are responsible for the decomposition of waste in thermal plasma are as follows: unimolecular, radical chain, and photochemical dissociation. The experimental data indicate that the decomposition mechanism is temperature dependent, and at the higher temperatures, a photochemical decomposition mechanism is incorporated.

In order to provide good mixing of the plasma with the processed waste, Knak et al. (1997) investigated a three-jet mixing chamber in which three electrical-arc plasma generators were operated as shown in Fig. 3. They used realindustrial residues containing methylene chloride and alcohol benzene mixture waste contaminated by colophony, which were introduced to the plasma reactor by an atomizer. They used different kinds of waste solutions like an aqueous solution and a solution in a polar organic solvent. Complete decomposition was obtained by using the polar organic solvent by energy consuming of $4.05 \mathrm{kWh} /$ $\mathrm{kg}$. Furthermore, toxic dioxins and carbon monoxide were not detected after treatment. More toxic compounds such as dioxin/furans were also eliminated compared to ordinary thermal methods for destruction of toxic halogen organic waste. They concluded that the destruction results are improved by modifying the physicochemical properties of the solution as well as using three electrical arc plasmas at the same time instead of one electrical arc plasma generator (previous work).

In the 1980s and 1990s, Westinghouse industrial plasma technology developed plasma pyrolysis reactor which could only destroy liquid wastes (Pfender 1999). The liquid wastes are injected into the downstream of the torch as shown in Fig. 4. The reactor works with a 1-MW nontransferred plasma torch, and the plasma gas is air. The unit is able to treat various wastes such as PCB (polychlorinated biphenyl), which is destroyed at a rate of up to $720 \mathrm{~m}^{3} / \mathrm{h}$ with a torch power of $850 \mathrm{~kW}$. They achieved $99.999999 \%$ destruction efficiency with particulate and acid emission well under the EPA guidelines (U.S. Environmental Protection Agency). 


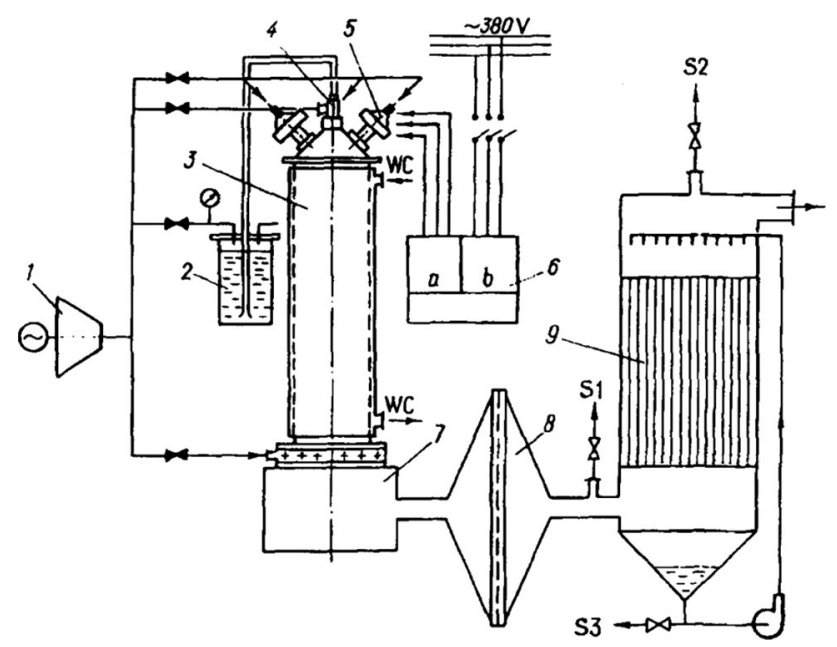

Fig. 3 Schematic drawing of the experimental setup for plasma thermal processing of toxic waste: 1 compressed-air feeding system, 2 liquid waste feeding system, 3 reactor, 4 atomizer, 5 plasma generators, 6 electrical power sources (Knak et al. 1997)

Starting in the 1990s, the PLASCON process was used in some commercial plants for waste treatment by thermal plasma (Heberlein and Murphy 2008). The liquid waste with an oxidizing gas is injected toward the end of the plasma torch as shown in Fig. 5. PLASCON technology was used to destroy the hazardous liquids in Australia (Murphy 1999). They treated real hazardous waste like organic liquids containing dichlorophenols, dioxins, and other organic species. The oxidizing gas prevents the formation of soot. After passing through reaction tube which provides for a sufficient residence time, the hot gases are quenched preventing the unwanted side reactions. A liquid spray is used for quenching the mixture after destruction.

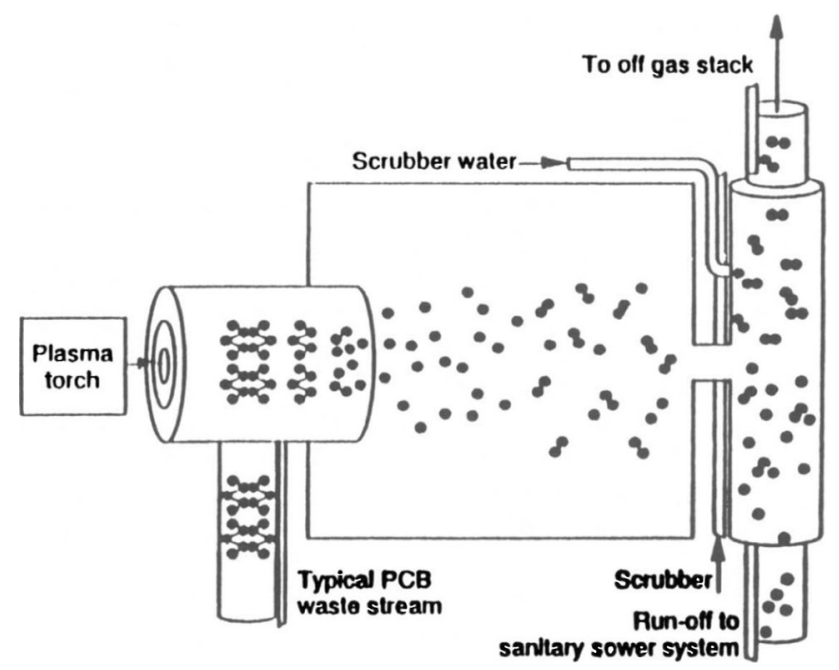

Fig. 4 Pyroplasma pyrolysis units developing by Westinghouse (Pfender 1999)
Then, cool gas passes through a caustic soda to remove acid gases. The liquid with high concentration of dioxins, PCBs, and other toxic chemicals can be treated by this technology with $99.99999 \%$ destruction and removal efficiencies (DRE). Moreover, the dioxin and furan emission level are less than $0.01 \mathrm{ngm}^{-3}$ toxic equivalents which is well below the strictest environmental standards in the world.

In another research, hydrocarbon solution is injected axially into the DC cascade plasma torch in power ranges from 1 to $5 \mathrm{~kW}$ (Pacheco et al. 2001). Valuable by-products such as energetic gas [syngas $\left(\mathrm{H}_{2}\right.$ and $\left.\mathrm{CO}\right)$ ] are produced form destruction of waste. They introduced three parameters for operation conditions that can be adjusted for the best results. These parameters include energy/mass, injection time, and feed rate. They concluded that the energy level for producing syngas should not be less than $0.58(\mathrm{~kJ} / \mathrm{kg})$. Also, at injection time $(<5.6 \mathrm{~min})$ and feeding rates $(<10.368 \mathrm{~kg} / \mathrm{h})$, solid by-products are not formed. In optimal condition, the gas products formed from the destruction of hydrocarbon solution are $\mathrm{H}_{2}, \mathrm{CH}_{4}, \mathrm{O}_{2}$, and $n \mathrm{C}_{8} \mathrm{H}_{18}$ with some solid (C) by-product which has commercial value.

As it was seen above, different methods can be used to have a well mixing between liquid and plasma and as a result, high destruction efficiency. These methods include the following: (a) liquid injection into the downstream of plasma; (b) liquid injection transversely to the plasma stream; (c) liquid injection with an oxidizing gas toward the end of the plasma torch, (d) using carrier gas; and (f) counter-flow injection. The efficiency of process can also be increased by modifying the physicochemical properties of the solution. Moreover, destruction efficiency can be increased by lowering the plasma gas flow rate (increasing the residence time) or increasing the arc jet current which leads to a temperature increase.

For the cases that used real hazardous material as treating sample (like PLASCON ${ }^{\mathrm{TM}}$ system and Westinghouse industrial plasma), thermal plasma show $99.99999 \%$ destruction and removal efficiencies (DRE) which is well under the RCRA for hazardous waste. The emission level of toxic product like dioxin and furan is also below the environmental standards. However, as times goes by, environmental standard for emission of degradation by-products becomes more and more strict, and hence, higher destruction efficiency with lower toxic by-product is required.

\section{Steam DC plasma}

Another remarkable factor for effective destruction is plasma gas. Air, $\mathrm{O}_{2}$, argon, and nitrogen can be used as plasma gas. Air is mostly used as plasma gas due to its 
Fig. 5 Schematic drawing of PLASCON process (Murphy 1999)

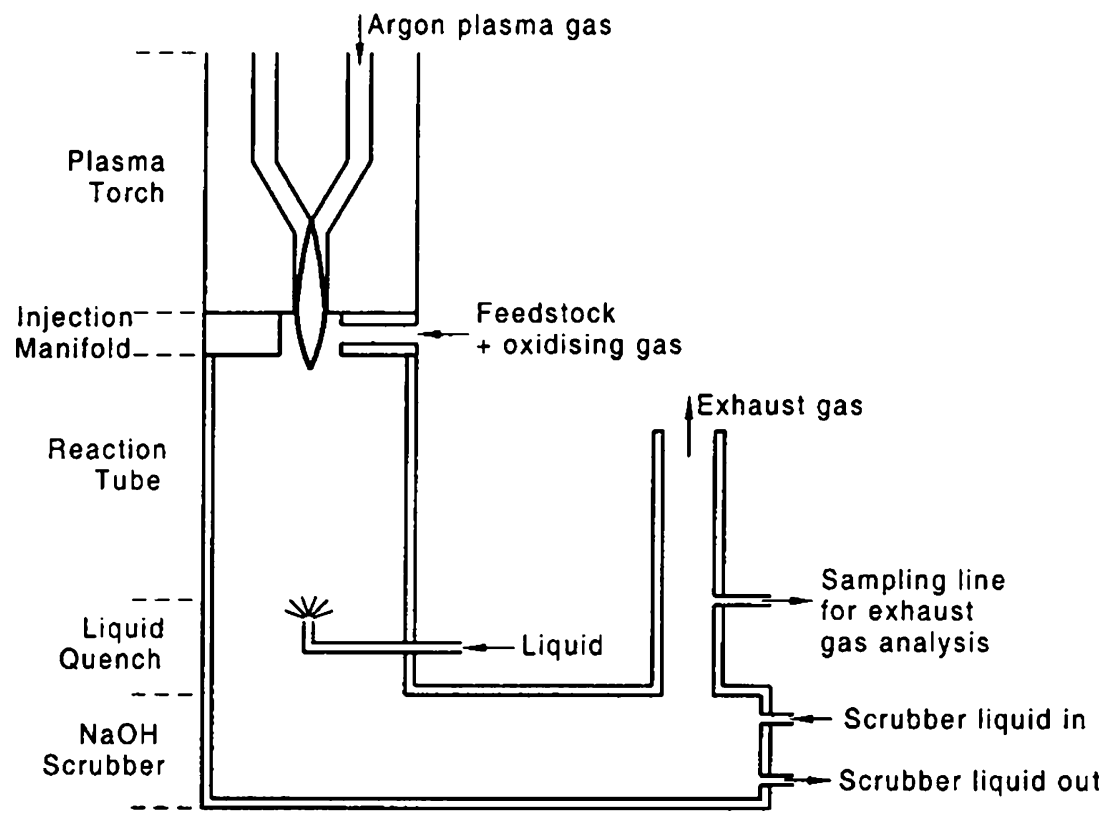

availability. But, it forms nitrogen oxides which are additional pollutants. Argon as an inert gas can be used in any treatment. It ionizes easily compared to the other plasma gases but reduces the power efficiency because of its high plasma temperature. Compared to inert gases, molecular gases such as $\mathrm{O}_{2}$ and steam require higher energy for dissociation and ionization. It leads to higher plasma enthalpy and less gas flow in the reactor for the same amount of plasma enthalpy compared to non-molecular gas. High plasma enthalpy is desirable for higher material feed and processing rates.

High temperature inside the plasma reactor will cause thermal or corrosive damage. In order to minimize these damages, conventional methods like air or water cooling are used. But they decrease the thermal efficiency because they remove the heat from the plasma. Thermal efficiency can be increased by using this removed heat by converting the cooling water to steam and using the steam as a supporting plasma gas. This method provides two purposes: (a) recovering a potentially substantial fraction of plasma heat, which normally is lost by a large flow of cooling water and, (b) producing dry super-heated steam for plasma gas. In DC arc torch, electrodes should also be cooled with a water-cooling system. The same method can also be used to increase the overall system efficiency.

In 2003, Seok-Wan et al. (2003) used non-transferred DC steam plasma with $100 \mathrm{~kW}$ torch power for PCBs treatment as shown in Fig. 6. In this system, the waste is jetted tangentially to steam plasma flame for increasing the contact between steam plasma and liquid waste. Due to oxidizing medium produced by steam plasma, nitrogen or argon should be used as the protection gas for tungsten cathode. High-temperature flows and concentrated free radicals with high reactivity are generated in the reactor. The high-reactive free radicals such as $\mathrm{OH}, \mathrm{O}$, and $\mathrm{H}$ in steam plasma flame increase the destruction efficiency. The DRE of PCBs in steam plasma is above $99.9999 \%$. The formation of the toxic by-products such as dioxins and furans which is inevitable in the conventional incineration is minimized by using steam plasma. The total toxic equivalent concentration of PCDD (polychlorinated dibenzodioxins)/PCDF (polychlorinated dibenzofurans) from steam plasma process was about $0.056 \mathrm{ng}$ TEQ/ $\mathrm{N} \mathrm{m}^{3}$, which is below emission standard of incineration (see Table 1). According to the results, the steam plasma torch process is more effective for converting hazardous waste to energy than the air plasma torch process with steam injection and the conventional incineration process. However, this system suffers from high electrode erosion due to using the oxidizing gases in DC arc torch. This corrosion decreases the electrode lifetime and contaminates the plasma.

In 2009, Watanabe's research group (Nishioka et al. 2009) in Tokyo institute of Technology investigated the decomposition mechanism of organics in water by DC water plasmas. They developed DC water plasma without using external steam generator (Fig. 7). DC arc plasma requires cooled water for electrode cooling system. In their system, the water in the electrode cooling system is heated up and evaporated to form the steam as a plasma-supporting gas. This leads to higher energy efficiency compared to conventional system. They use a cathode of hafnium embedded into a copper rod and a nozzle-type copper anode. Hafnium is used as the cathode material because it can prevent erosion and lead to a longer operating time in an oxidative atmosphere. They use methanol and ethanol as a model substance of water-soluble organic compound. The $50 \mathrm{wt} \%$ 
Fig. 6 Schematic diagram of steam plasma system for liquid hazardous waste treatment (Seok-Wan et al. 2003)

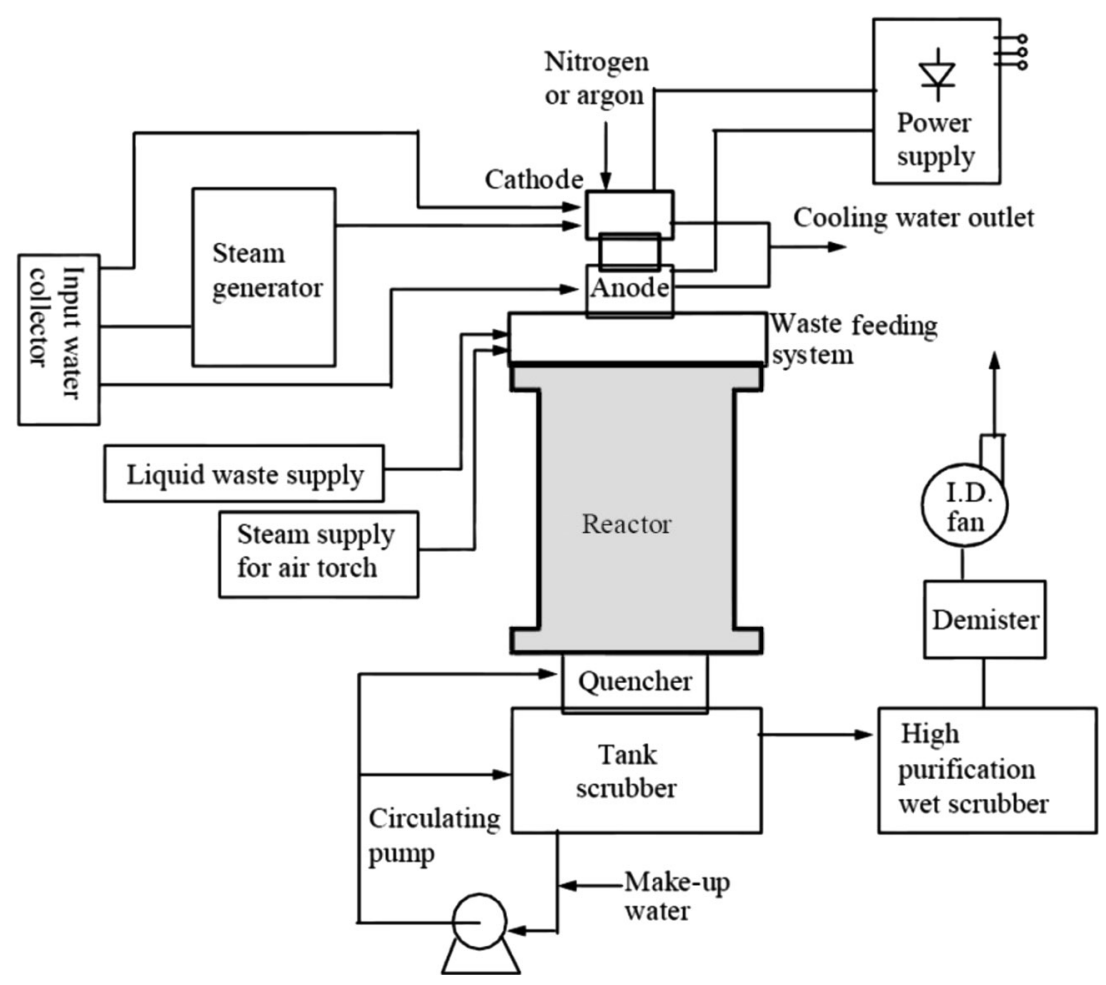

of carbon in ethanol is converted to solid carbon, while the solid carbon formation from methanol is negligible. $\mathrm{H}_{2}, \mathrm{CO}$, and $\mathrm{CO}_{2}$ are the main gases after the decomposition. The high mole fraction of $\mathrm{H}_{2}(>60 \%)$ in produced gas shows that liquid wastes can be used for producing syngas. A new method for injecting material into plasma is also used in this system. Organic compounds are mixed with water as plasma-supporting gas. The solution (alcohol) is injected into the discharge region immediately after the evaporation by the extensive heat from the anode. The solution vapor is decomposed by the water plasma in the high-temperature zone after the discharge region. The residence time in the high temperature zone for treating sample was around $1 \mathrm{~ms}$. Dissociation of treated compound is limited in the high temperature region, and most of the dissociation in the form of oxidation occurs in the following region (low temperature region). This method is more efficient than conventional injection into thermal plasmas. Eliminating the need for any gas supply unit and external steam generator can lead to a portable light-weight plasma generation system with highenergy efficiency.

In the same research group, Yuan et al. (2010) used DC water plasma at atmospheric pressure for treating aqueous phenol. The DC water plasma is operated without injection of inert gases or air and cooling controlled and pressurecontrolled devices. It means that the energy consumption is lower than traditional thermal plasma devices (high-energy efficiency of $90 \%$ ). The cathode is a hafnium (Hf) embedded into a copper rod in a bullet shape with a length of

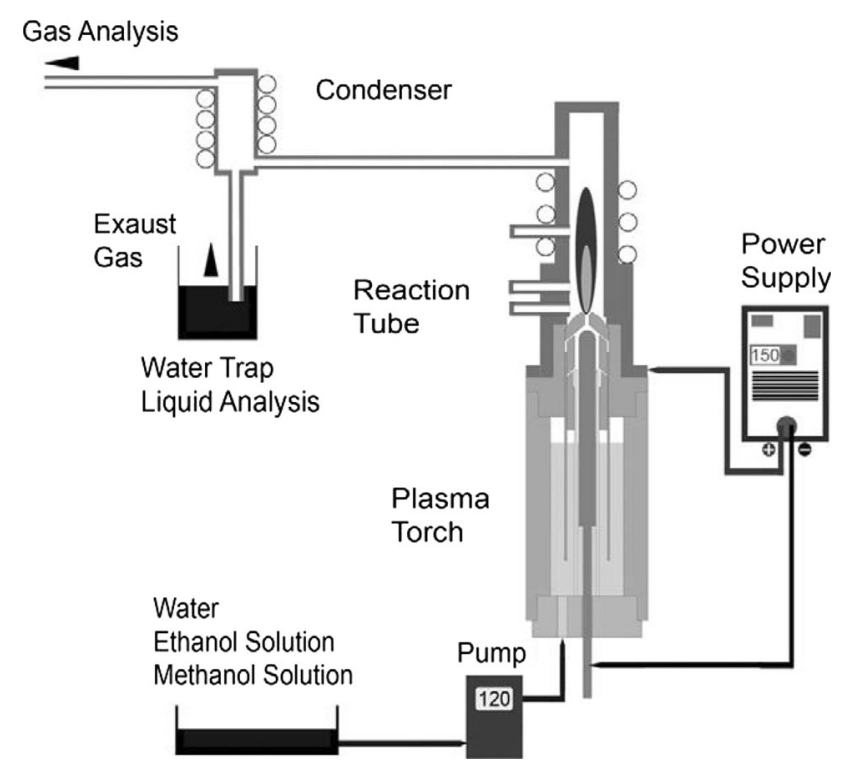

Fig. 7 Schematic drawing of experimental apparatus of DC water plasma (Nishioka et al. 2009)

$20 \mathrm{~mm}$, and the diameters of the $\mathrm{Hf}$ and $\mathrm{Cu}$ rod are 1 and $7 \mathrm{~mm}$, respectively. A phenol solution of $5.23 \times 10^{-3}$ to $52.8 \times 10^{-3} \mathrm{~kg} / \mathrm{m}^{3}$ can be decomposed by the DC water plasma torch with energy efficiencies of $1.9 \times 10^{-8}$ to $2.2 \times 10^{-8} \mathrm{~mol} \mathrm{~J}^{-1}$. DC water plasma shows a good performance on removal of chemical oxygen demand (COD) and total organic carbon, (TOC) and $\mathrm{H}_{2}, \mathrm{CO}$, and $\mathrm{CO}_{2}$ are the major products in the gaseous effluent. $\mathrm{HCHO}$ and $\mathrm{HCOOH}$ 
are the major by-products in the liquid effluents. However, at a high loading of phenol condition, $\mathrm{C}_{2} \mathrm{H}_{2}$ and $\mathrm{C}_{6} \mathrm{H}_{6}$ will be formed. The content of syngas $\left(\mathrm{H}_{2}\right.$ and $\left.\mathrm{CO}\right)$ is about $70 \%$.

Decomposition mechanism of phenol in water plasma by DC discharge at atmospheric pressure was investigated by Narengerile et al. (2011). They found that understanding of kinetic behaviors, including the reactions which occur during a quenching period and complete pyrolysis, is an important unknown aspect in the thermal plasma waste treatment. The arc current has a strong effect on TOC and COD reduction for the phenol decomposition by the water plasma. They show that phenol decomposition mechanism in thermal plasmas is different from that in the non-thermal plasma and in the advanced oxidation processes (AOPs). The main reaction is electronic dissociation in arc region which produce $\mathrm{C}_{6} \mathrm{H}_{5} \mathrm{O}$ radical. Chemical oxidation or reduction in plasma flame region is the second reaction which forms $\mathrm{C}_{6} \mathrm{H}_{5} \mathrm{O}$ and $\mathrm{C}_{6} \mathrm{H}_{6}$. After phenol decomposition, intermediate species are produced and recombined with $\mathrm{H}$ or oxidized by $\mathrm{OH}$ forming stable unwanted compounds in plasma flame region.

Recently, acetone decomposition was investigated by using water plasma at atmospheric pressure (Narengerile and Watanabe 2012). The torch operated in the absence of carrier gases or air injection and cooling controlled systems. Also, they proposed a mechanism for decomposition of acetone. The plasma temperature and the residence time in the high-temperature region decrease by reducing the arc current. Therefore, the lower current arc leads to lower decomposition rate. The major decomposition products in gas phase are as follows: $\mathrm{H}_{2}, \mathrm{CO}_{2}$, and $\mathrm{CO}$. At a higher arc current, the concentration of $\mathrm{CO}_{2}$ and $\mathrm{H}_{2}$ increase because of a stronger oxidative environment. Accordingly, the water plasma was considered to be suitable method for the decomposition of volatile organic compounds (VOCs) with high concentrations. In 2012, they used this system for treating water-insoluble organic compound like 1-decanol (Choi and Watanabe 2012). For mixing 1-decanol with water, they used a surfactant. The emulsion is used for feeding liquid and plasma-forming gas of the water plasma jet. DRE of $99.9999 \%$ is achieved by this system. The system can treat water-insoluble compound as well as water-soluble compound. $\mathrm{H}_{2}, \mathrm{CO}, \mathrm{CO}_{2}, \mathrm{CH}_{4}$, neutral liquids, and solid carbon are the decomposition products. They found that in the higher arc current, the carbon in 1-decanol emulsion converts to $\mathrm{CO}$ and $\mathrm{CO}_{2}$ gases easier than carbon in water-soluble organic compound.

Although, using steam as plasma gas shows well mixing as well as high heat and mass transfer between plasma jet and solution, but oxidative medium of steam decreases electrode life. Therefore, a new effective method with high level of mixing and without direct contact of solutions with electrodes is required. Moreover, in this method, the liquid should reach high temperature without damaging the reactor. Submerged plasma therefore suggested as a novel method to overcome these problems which will be discussed in the following section.

\section{Plasma jet injection into volume of liquid (submerged} plasma)

This novel reactor with direct contact between plasma and solution was designed for the first time by Bernier et al. (2001). In this novel reactor, different methods for interaction between plasma and liquid are used. Plasma jet is injected to the solution bulk instead of previous methods which injected the solution into the plasma jet. As it can be observed in Fig. 8, a draft tube is placed above the torch for the maximum liquid recirculation and increasing the contact time and mixing level between plasma gas and liquid phase. Thermal hydrolysis occurs in the high temperature zone (submerged plasma plume), while the bulk temperature of solution remains low.

Effect of different operation parameters on treatment of cyanide contaminated liquid solutions are studied by using this novel thermal plasma reactor (Fortin et al. 2000). Most of the reactions take place in plasma zone and inside the draft tube. These experiments indicated an improvement in treatment of contaminated solutions by using the new submerged plasma reactor. The improvements include the presence of both steep thermal gradients and reaction photocatalysis by the plasma UV radiation and well mixing

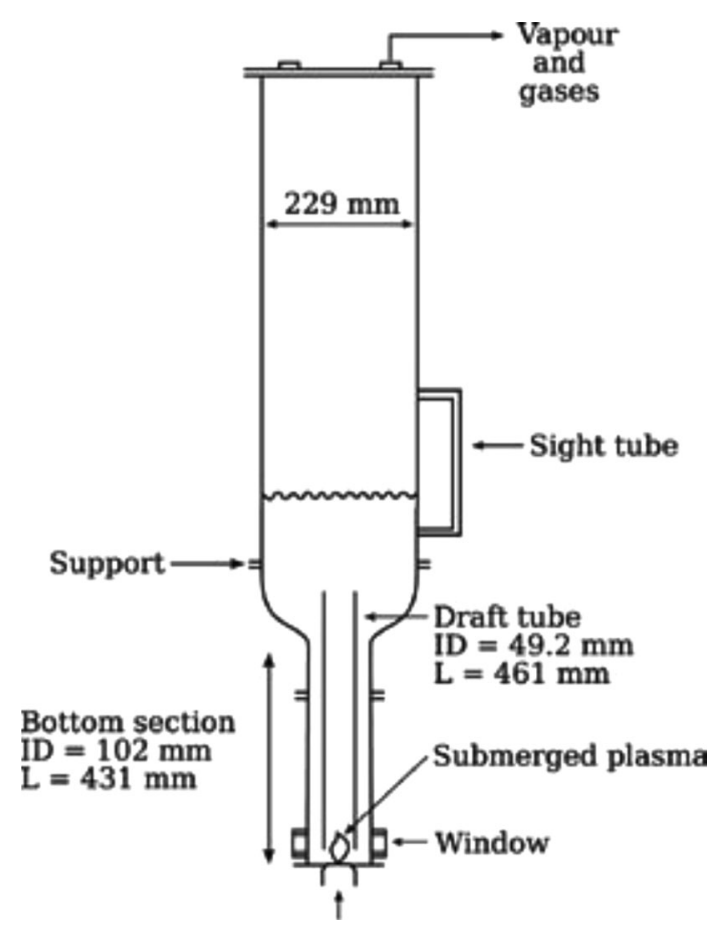

Fig. 8 Schematic drawing of submerged plasma reactor with draft tube (Munholand et al. 2006) 
with long residence time between solution and plasma. Moreover, the process is not sensitive to initial concentration of the wastes.

The ability of submerged thermal air plasma for destruction of organic salts containing synthetic Bayer liquor is investigated by Soucy's research group (Munholand et al. 2006). Submerged thermal plasma provides direct thermal and oxidizing contact between plasma, oxidizing gas, and organics in solution. They show that the concentration of organic salts decreases up to $65 \%$ after 24 min treatment. All organic acid are decomposed significantly in the plasma reactor. Therefore, submerged thermal plasma has significant ability for organic removal from solutions.

Submerged thermal plasma was also employed for oxidation of Bayer spent evaporated liquors by two different plasma gases: air and oxygen (Armstrong and Soucy 2007). The two plasma gases give similar results for caustic loss which indicates similar overall organic degradation. When oxygen is the plasma gas, the overall plasma temperature is higher due to the lower dissociation energy of oxygen compared with air. Therefore, there are more free radicals that contribute to the degradation of the organics in solution. Moreover, air treatment shows a smaller carbonate increase than oxygen treatment and smaller total organic carbon (TOC) decrease. Oxalate generation for air plasma is lower compared to oxygen plasma. According to these data, plasma treatment decomposed Bayer organics in different pathway with different end-products compared to wet oxidation (WO).

To produce valuable by-product in waste destruction process by submerged thermal plasma, Boudesocque et al. (2007) have designed an experimental facility. They study the performance of submerged non-transferred arc plasma torch in decontamination and gasification of aqueous organic waste. UV radiation and oxidizing radical species $\left(\mathrm{OH}^{\circ}, \mathrm{O}^{\circ}\right.$, etc. $)$, which are produced by submerged plasma, have a significant role for treating contaminants. They treat two kinds of contaminated aqueous solution such as dye molecule (methylene blue) and chlorinated molecules (chlorophenol). Moreover, concentrated aqueous solutions such as sucrose are partially oxidized and produced syngas. Increasing the available power and the plasma gas flow rate do not accelerate the degradation. However, increasing the solution flow velocity near the plasma jet by using the recirculation device can enhance the degradation rate. Therefore, well mixing of plasma jet and solution has a positive influence on the efficiency of the process. The main advantage of this system is the ability to reach high temperature in a cold reactor and no production of polycyclic aromatic hydrocarbons (PAH) due to high quench rate (about $107 \mathrm{~K} \mathrm{~s}^{-1}$ ). The submerged plasma jet is already capable of gasifying several kilograms of sucrose in aqueous solution per hour.

Recently, submerged thermal plasma jet was tested for treating radioactive organic liquid waste (Mabrouk et al. 2012). In this system, an oxygen thermal plasma jet is injected into a bulk of liquid. The cathode is made of tungsten, and anode is made of copper. The cathode tip is protected by argon flow. The plasma torch is disposed to the bottom of water-jacket reactor. Three different wastes were treated: a mixture of tributylphosphate (TBP) and dodecane, a perfluoropolyether oil (PFPE), and trichloroethylene (TCE). Zirconium is used as a surrogate of plutonium. Better than $99.9 \%$, process efficiency is achieved for feed rate of $0.004 \mathrm{~m}^{3} / \mathrm{h}$ without trace of zirconium in the condensed residues.

The removal of organic impurities such as phenol and humic acids from the technological aluminates solution is investigated by flowing high-speed oxidizing thermal plasma jet into the solution bulk (Samokhin et al. 2010). A submerged DC arc with water-cooling jacket is used (Fig. 9). This treatment decreases the concentration of dissolved organic compounds. Increasing the enthalpy of the plasma jet leads to the increase in the outflow velocity of jet into liquid and the content of active species atoms and radicals. It increases the oxidation rate of organic compounds in the solution. Therefore, the oxidation rate of organic impurities depends on the properties of the organic compound and characteristics of the process such as the composition of the plasma-forming gas, enthalpy of the plasma jet, and starting impurity concentration. The chemical consumption of oxygen (CCO) contents decreases more than $60 \%$ under the effect of the thermal plasma jet. The degradation of starting organic compounds was more than $80 \%$. However, the laboratory installation is not able to treat the highly concentrated technological aluminate solutions due to the strong-foam formation.

The treatment of liquid contaminants by plasma can be explained briefly. Plasma transfers high electrical energy into liquid phase and generates highly active species such as hydroxyl radicals, hydrogen peroxide, ozone, etc.(Munholand et al. 2006). The interaction of free radicals such as $\mathrm{OH}^{-}$with impurities removes liquid contaminates. Therefore, removing liquid contaminants by thermal plasma depends on the intensity of mass transfer in the gas phase from the plasma bulk toward the gas-liquid interface. Increasing mass transfer rate can be achieved by intense turbulence in the gas-liquid system and a decrease in the characteristic size of the gas volume (Samokhin et al. 2010). Therefore, well mixing of plasma jet and solution has a positive influence on the efficiency of the process (Boudesocque et al. 2007). As another important parameter, long residence time of fluid in the high temperature 


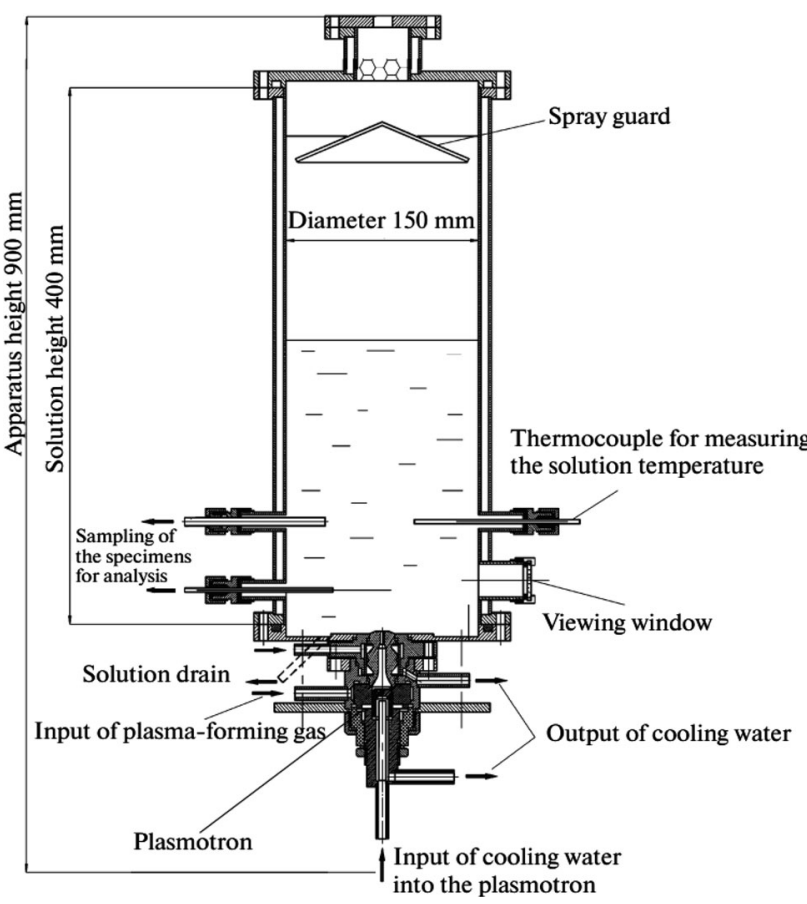

Fig. 9 Appearance of the experimental reactor for the plasma treatment of aqueous solutions (Samokhin et al. 2010)

region is required for ensuring complete breakdown of the material.

Moreover, the solution can be injected into plasma jet in different ways. Using atomizer for introducing solution to plasma due to making the liquid droplets and providing high surface area between waste and plasma plume offers high mixing level. Liquid vaporization helps mixing which leads to higher waste destruction. Also, in the case of steam plasma in which solution is mixed with water as plasmasupporting gas, high mixing level and high destruction efficiency are achieved. Submerged plasma is also used for making the interaction between liquid and plasma jet (Fortin et al. 2000; Yargeau et al. 2004; Soucy et al. 2006; Armstrong and Soucy 2007; Boudesocque et al. 2007; Mabrouk et al. 2012). To increase turbulency and mixing reactants with plasma gas, a draft tube is placed above the plasma torch. This will lead to large recirculation inside the reactor and long residence time which has a positive influence on the efficiency of the process. Submerged plasma has many advantages compared to solution injection method including a) high temperature plasma zone but cold reactor in bulk (high-energy efficiency) and b) high concentration of radical leading to high chemical reaction rates.

Stable arc is also an important factor for plasma arc technology. For having a stable arc, the plasma gas flow and electrical power should be well balanced. Air, $\mathrm{O}_{2}$, argon, nitrogen, and in some cases steam are used as plasma gas in the above works. The choice of plasma gas is normally based on reactivity, gas enthalpy, and availability. High plasma enthalpy is desirable for higher material feed rate and higher materials processing rates. For example, steam plasma temperature is significantly lower than argon or other inert gas. It leads to lower radiation heat loss. Therefore, steam plasma has the highest theoretical power efficiencies (ratio of power in plasma jet to line power) compared to argon or other inert gases. This will lead to higher overall energy efficiency and higher amount of treated waste for a given electrical power level. Therefore, oxygen and steam can be good options for plasma gas. However, using oxygen and steam as plasma gas decrease electrode life due to the oxidative medium which is an important issue for DC torch. Nitrogen and argon as plasma gas lead to longer electrode life compared to oxidative gases. Seok-Wan et al. (2003) used nitrogen and argon as protection gas of tungsten cathode for having longer life in oxidizing medium. However, using protection gases are not favorable for industrial applications due to increased costs. Watanabe's research group (Yuan et al. 2010) used hafnium embedded into copper rod as cathode material for solving the cathode erosion problem in the oxidative medium. This method can prevent the cathode erosion more effectively. However, having electrode with longer life is still required for working in an oxidative medium.

As it can be seen in Table 3, non-transferred arc processes are chosen for most of the above technologies for treating liquids due to having more uniform temperature distribution and arc stability, the availability of reactive species, simple mechanical control requirements, and greater bulk gas heating capability. Furthermore, the waste with high organics concentration can be treated by nontransferred plasma torch. In most cases, a low toxic test liquid was chosen due to safety issues. Real hazardous materials as test liquid are chosen only in a few of these research works. In these cases, destruction and removal efficiencies (DRE) of $99.99999 \%$ are achieved. Moreover, the emission level of toxic product like dioxin and furan was well below the strictest environmental standards in the world.

\section{Radio frequency (RF) induction plasma}

RF plasma is generated via electromagnetic coupling of the input electrical energy into the discharge medium. The plasma torch is constructed of a cylindrical plasma tube which cooled by water. The electrical energy is sent to the torch through the use of a water-cooled induction coil. An oscillating magnetic field is generated by connecting the coil to the RF power source. It will couple into the partially ionized gas load flowing within the discharge cavity and providing for its ohmic heating in order to sustain the 
plasma. RF plasmas use inductive coupling to transfer energy to plasma gas and are characterized by the absence of electrodes. Hence, it can operate in a wide range of corrosive atmospheres such as reducing and oxidizing (Gomez et al. 2009; Huang and Tang 2007). They are very compact and deliver huge amount of input energy (by electrical conduction coil) per volume. They have the ability to inject feedstock material into or through the plasma region directly. This plasma has many advantages for treating liquid wastes including simple waste injection methods and having large specific plasma volume with low plasma gas velocity. These advantages lead to the better controlling of chemistry process and increased residence time (Soucy et al. 1998).

The commercial application of RF plasma includes plasma spray coatings and deposition, crystal growth, sintering, synthesis of high purity ceramics, synthesis of ultrafine ultrapure powders, and synthesis of titanium dioxide pigments.

Like the DC arc plasma, feed introduction and plasma gas are important for having high efficiency destruction. The quality of atomization also plays a key role in the process. Fine atomization leads to complete decomposition due to enhanced contact between the liquid feed and the plasma gases. Steam can be used as plasma gas in RF plasma due to having no electrodes and no corrosion risk. But this technology suffers from low energy efficiency due to high-energy loss during plasma generation and large plasma volume. By solving this problem, RF plasma can be used widely for liquid treatment. Much research is still needed to reach this point; however, only few works have been published to investigate the RF plasma systems for liquid treatment.

Plasma Technology, Inc. (PTI) has developed the plasma energy recycle and conversion $\left(\mathrm{PERC}^{\mathrm{TM}}\right)$ treatment process (Smith et al. 1995). Hazardous military wastes were tested to demonstrate the feasibility of a plasma process for converting waste to useful materials, such as syngas (mixture of $\mathrm{CO}$ and $\mathrm{H}_{2}$ ). Several kinds of wastes were tested such as nitrogen-containing liquid rocket fuel unsymmetrical dimethyl hydrazine (UDMH). They used an inductively coupled plasma torch as a heat source at $25-750 \mathrm{~kW}$ power level with a variety of gases including argon, nitrogen, oxygen, air, and mixture of these gases as plasma gas. Two reactors were used: The first reactor is continuous stirred-tank reactor model (CSTR) with ICP (inductively coupled plasma) torch for pyrolysis, and the second reactor is a plug-flow reactor model (PFR) where the pyrolysis was completed. Under this condition, more than $99.99999 \%$ destruction and removal Efficiency (DRE) was obtained which is from 10 to 100 times higher than that required by RCRA. Overall, efficiency of power transfer to the plasma was $30 \%$. The produced nitrogen oxides $\left(\mathrm{NO}_{\mathrm{x}}\right)$ are extremely low compared to combustion or DC arc plasma with air plasma gas. This is one of the main advantages of the (PERC $\left.{ }^{\mathrm{TM}}\right)$ treatment. Also, the volume of produced gases is low compared to the incineration process. Due to safety issues in treatment of radioactive wastes, replacement of the parts close to the main treatment reaction is prohibited. Therefore, ICP plasma can be a good option for treatment of radioactive wastes because of having no consumable parts and no need for part replacement.

In 1997, radio frequency (RF) energy inductively coupled to high-temperature plasma at ambient pressures was developed for processing of surrogate hazardous liquid or gaseous organic waste (Huhn et al. 1997). Oxygen, argon, air, and nitrogen can be used as plasma gas in this system. Plasma power level was $15-100 \mathrm{~kW}$. A plasma torch efficiency of $56 \%$ was achieved. A halogenated organic compound, carbon tetrachloride, was processed as waste sample material in compliance with U.S. Environmental Protection Agency (EPA) analytical protocol. Destruction efficiency results were $99.99999 \%$ by treating at $55 \mathrm{~kW}$ plasma power level by using ambient air as plasma gas, $1.56 \mathrm{~m}^{3} / \mathrm{h}$ plasma sheath gas flows, with $0.72 \mathrm{~m}^{3} / \mathrm{h} \mathrm{CCl}_{4}$ injection rate at the front of plasma column.

An induction plasma reactor for treatment of aromatic liquid waste was developed by Soucy et al. (1998). They demonstrated technical feasibility of toluene reforming by using a $40 \mathrm{~kW}$ plasma high frequency (h.f.) at atmospheric pressure. It can also be used at power levels up to $100 \mathrm{~kW}$. Argon was used as the central plasma gas. Liquid toluene and water were sprayed axially through a water-cooled plain jet. Toluene DRE of $99.99 \%$ was achieved by low production of solid carbon, polycyclic aromatic hydrocarbons (PAH), and benzene. The production of solid carbon and benzene increases by increasing the reactor pressure. $\mathrm{CO}, \mathrm{H}_{2}, \mathrm{C}_{2} \mathrm{H}_{2}, \mathrm{CH}_{4}, \mathrm{C}_{4} \mathrm{H}_{2}$, and $\mathrm{CO}_{2}$ were generated in the gas phase. They mentioned that induction plasma technologies provide lower overall energy efficiencies compared to DC plasma torch. Hence, this draw back requires more research work.

The treatment of water-based toxic waste using induction plasma technology was investigated by Yargeau et al. (1999). Ethylene glycol was chosen as treating material based on low toxicity, complete solubility in water, low viscosity, low partial pressure, well-known chemistry, and safety issue. Argon or oxygen, at the rate of $720 \mathrm{~m}^{3} / \mathrm{h}$, was the atomization gas. The RF power supply was $30-50 \mathrm{~kW}$ unit with an oscillator frequency of $3-5 \mathrm{MHz}$, reactor pressure 33.3 and $66.7 \mathrm{kPa}$, and solution feed rate $3-6 \mathrm{~kg} /$ h. The torch efficiency was, on average, around $72 \%$. Syngas was a major product of the process. The results showed that the quality of atomization plays a key role in the process. Fine atomization leads to complete 
decomposition due to enhanced contact between the liquid feed, and the plasma gases and poor atomization reduced the DRE values to $80-85 \%$. Higher plasma power, lower pressure, and feeding rate also lead to higher DRE. They showed DRE value can reach $100 \%$ with a good atomizer.

As it was mentioned in the previous section, a submerged plasma system can potentially have high-energy efficiency and high destruction efficiency. Therefore, recently some efforts have been done to produce submerged RF plasma in solution. Maehara et al. (2006) generated radio frequency plasma in submerged mode as shown in Fig. 10. They showed that RF plasma in water can be used for decomposing the organic matter in water. They also generated RF plasma in pure water, tap water, and $\mathrm{NaCl}$ solution at atmospheric pressure. The colored water containing methylene blue was used as a treating sample. The frequency is $13.56 \mathrm{MHz}$, and the maximum $\mathrm{RF}$ power is $1 \mathrm{~kW}$. The temperature of plasma in water was around 4,000-4,500 K. Decomposition of organic material can be detected by the absorbance spectra of the colored water before and after plasma treatment. Methylene blue exposed to plasma degraded gradually for 3 weeks. Therefore, the RF plasma in water may be useful for purging organic matter in contaminated water. They showed that $\mathrm{OH}$ radicals were formed from water when the solution was exposed to plasma. $\mathrm{OH}$ radicals directly reacted with organic compounds in a various ways. Other active species (e.g., $\mathrm{H}$ and $\mathrm{O}$ radicals, etc.) may help the decomposition. They suggested that generated active species such as $\mathrm{OH}$ radical in the plasma causes the decomposition of the chemical reactants. Increasing the RF power leads to increase the intensity of the spectral line from $\mathrm{OH}$ radical and the fraction of decomposition of methylene blue (Maehara et al. 2008). This shows that $\mathrm{OH}$ radical may play an important role in the degradation. Also, UV radiation and $\mathrm{O}$ radical may affect the degradation of organic. Hydrogen peroxide is also produced by RF plasma

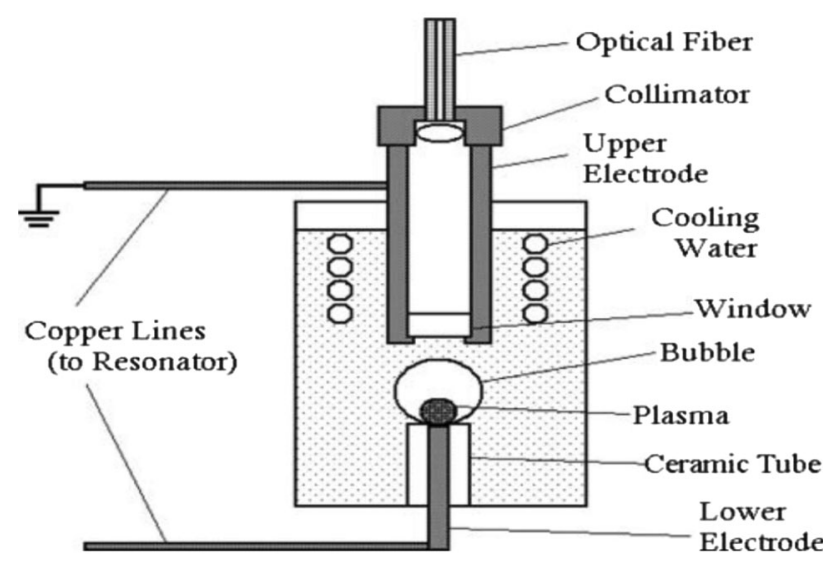

Fig. 10 Schematic view of experimental setup (Maehara et al. 2008) which plays an important role for degradation of methylene blue after exposition to plasma. In another work (Maehara et al. 2010), RF plasma and ultraviolet (UV) irradiation from a mercury vapor lamp were used simultaneously for degradation of methylene blue in water. The lamp without power emitted weak UV light because of the mercury vapor excitation by stray RF power. They observed that methylene blue degradation enhanced significantly by using both RF plasma and UV irradiation. Moreover, in the case of using the lamp without power, the degradation of methylene blue was enhanced. This enhancement was related to the reproduction of $\mathrm{OH}$ radical from hydrogen peroxide by photocatalysis process. The required hydrogen peroxide for reproducing $\mathrm{OH}$ radical was produced previously by the recombination of $\mathrm{OH}$ radicals around the plasma.

RF plasma has a great flexibility to manipulate or manage chemical reactions and reformation. The heat input per unit volume flow of gas for DC and RF plasmas is very high compared to combustion systems. Among these two types of plasmas, DC plasma shows less heat input per unit volume flow of gas compared to electrode-less RF plasma system due to the direct contact of electrodes to the plasma column. The high heat input per unit volume of RF plasma leads to a smaller and more compact physical structure for this system. Decreasing the volume of reactor at a given gas flow rate can increase the turbulence which leads to higher process efficiency. Also, the volume of the required gas flow is reduced for the same amount of heat input. Therefore, an electrode-less induction steam plasma which shows the advantage of steam plasma without the disadvantage of electrode erosion can be a good option for liquid treatment. But the major disadvantage of the RF plasma process for liquid treatment lies on the low torch efficiency compared to the DC torch plasma.

Thermal plasma patents for liquid and solution treatment

A number of patents propose thermal plasma as a method for treating liquid waste. A plasma method was presented for pyrolysis the liquid waste (Chang et al. 1989). This invention presents a method for destruction of waste materials mixed with water, methanol, or their mixture. For treating this mixture, it is injected into a plasma torch with a temperature more than $5,000{ }^{\circ} \mathrm{C}$. An electrical arc extended between spaced electrodes generates heat for the destruction of hazardous and toxic wastes containing polychlorobenzene biphenyl (PCB) and trichlorobenzene (TCB). The torch includes a pair of cylindrical electrodes which are longitudinally spaced by a gap. The pressurized gas is injected to blow an electrical arc. The annular nozzle is located between the electrode and a burner chamber. Pure 
oxygen (not air) is used as the torch gas to prevent the cyanide formation (that generally is produced by the nitrogen present in the air). The extremely high temperature and ultraviolet radiation resulting from the ionized gases in plasma can provide the enough bond-breaking energy to destroy the wastes. Mixing the feed and waste material with water or methanol increases the throughput of waste treatment 10 times faster compared to non-mixing methods. However, the processing of the waste mixed with water/ methanol will increase the complexity of the treatment process. The gas product is a mixture of $\mathrm{CO}_{2}, \mathrm{H}_{2} \mathrm{O}$, and $\mathrm{N}_{2}$ which is released into the atmosphere as a non toxic gas.

In 1991, Kulkarni (1990) presented a method for treating liquid hazardous waste in the absence of oxygen by exposing the waste solution to a high temperature plasma arc. The waste material is injected into the center of the torch which has the highest temperature. The torch includes a pair of cylindrical electrodes, which are longitudinally spaced by a gap and are cooled by a plurality of water tubes. They converted hazardous material to non-hazardous components. Nitrogen or argon is used as plasma gas. Hydrogen is also employed for treating waste materials containing oxygen. For maintaining the plasma torch at relatively cool temperature, they used continuous water circulation. The hazardous material is fed to plasma torch through the feed line with the flow rate of $0.68-1.36 \mathrm{~m}^{3} / \mathrm{h}$. Plasma temperature is set in the range of $5,000-15,000{ }^{\circ} \mathrm{C}$. In these temperatures, all organic and inorganic materials are converted into individual components. The by-product of conversion of hazardous material may include $\mathrm{N}_{2}, \mathrm{H}_{2}$, $\mathrm{CO}_{2}$, and $\mathrm{CH}_{4}$. They mentioned that the invention is totally environmentally safe, and there is no way to release undesirable material to atmosphere after treating by this method.

As it was discussed before, conventional methods like air or water cooling are used to cool the plasma reactor to prevent thermal or corrosive damages. The cooling process leads to strong radial temperature gradient between the core zone of the plasma jet and the reactor wall. The cold zone near the wall display considerably lower reaction rates and in some case provides an escaping zone for toxins from treatment. However, Dummersdorf et al. (1992) used the air as a cooling system starting in the lower part of the reactor. This method increases the average temperature of the plasma reaction stage (increase the wall temperature), which prevents the escape of non-treated toxins near the wall. The reactive plasma flow is mixed with the heated cooling air in the secondary reaction stage. Therefore, cooling medium (air) can be used as heated oxidizing agent in the secondary reaction stage right after the plasma reaction stage to increase the thermal efficiency. This method is used for treating liquid, solid, and gas hazardous wastes containing at least a member of the group of fluorinated and chlorinated hydrocarbons (which are stable up to $1,300{ }^{\circ} \mathrm{C}$ ). Gaseous, liquid, and pasty wastes are introduced directly into steam plasma jet for a period of $10^{-3} \mathrm{~s}$ followed by immediate introduction into an oxidizing medium at the temperature of $1,500{ }^{\circ} \mathrm{C}$ for $10^{-2} \mathrm{~s}$. The steam plasma affects thermally and chemically on the waste, which leads to rapid reactions between steam and wastes. The larger molecules of the toxins are converted into smaller fragments due to thermal effect of plasma. Next, these smaller fragments are broken with highly reactive hydrogen atoms and the chemical attack of oxygen-containing radicals such as $\mathrm{HO}_{2}, \mathrm{OH}, \mathrm{O}$, or $\mathrm{O}_{2}$ and form stable compounds such as $\mathrm{CO}$ and $\mathrm{H}_{2}$. A $100 \%$ detoxification may be obtained by this invention.

In 1992, a method for thermal decomposition of waste material is investigated by induction arc chamber (Holden et al. 1992). This invention provides a simple and effective method for waste decomposition especially for thermally stable chemical compounds such as PCBs and other toxic components. The apparatus consists of an induction arc chamber including a thermal decomposition cavity and plurality of electrodes. A plurality of electrodes is supported by the induction arc chamber. When the electrode is electrically energized, a high-temperature turbulent zone is created in the thermal decomposition cavity of induction arc chamber. Various waste materials include solids, liquids, and gases can be introduced into thermal decomposition cavity. They are in contact with high-temperature turbulent zone for a period of time for decomposition. Gas products resulted from decomposition of wastes are exhausted rapidly from the induction arc chamber to prevent the formation of toxic by-products.

Moody et al. (1993) invented a method for destruction of liquid chemical waste by oxidizing it in a plasma flame. Fine droplet liquid waste is introduced into plasma flame via two atomizer which uses oxygen as a carrier gas. Carrier gas can also be any convenient gas such as nitrogen or air. The amount of oxygen is at least $30 \%$ more than required for complete combustion of the waste. The reaction mixture temperature is $1,450{ }^{\circ} \mathrm{C}$ for $2 \mathrm{~ms}$. Then, the reaction products are cooled rapidly to temperature below $300{ }^{\circ} \mathrm{C}$ in order to prevent the formation of toxic products such as dioxins. The plasma flame heats the gas by a pair of electrodes with a DC current. The energy transferred to gas stream varies from 4 to $14 \mathrm{MJ} / \mathrm{kg}$. Any type of reactor can be used for this system. Cooling the reactor wall by air or water prevents reactor thermal damage or corrosive. By using the tube reactor, $99.85 \%$ destruction efficiency is reached for the treatment of ethyl alcohol with 0.108 molar ratios in water, $0.72 \mathrm{~kg} / \mathrm{min}$ total mass flow, and residence time of $4.14 \mathrm{~ms}$.

The main objective of the Chang et al.'s work in 1994 is to provide a method for treating liquid waste that can be 
easily operated and controlled (Chang et al. 1994). This method is suitable for processing small amounts of waste. Liquid waste is injected directly to the plasma torch. This system uses high temperature generated by plasma torch for treating waste in short period of time without using large amount of air. They presented the small apparatus for liquid waste treatment which can be easily controlled and operated with no direct contact between electrodes and waste. Plasma apparatus includes a jetting device with transporting tubes for directly transporting and jetting liquid toward plasma torch. The waste materials are decomposed into atoms or simple molecule such as $\mathrm{H}_{2}$, $\mathrm{CO}, \mathrm{CO}_{2}$, and $\mathrm{HCl}$ which after removing the acid can be released to the atmosphere.

A modification of plasma energy recycle and conversion (PERC) reactor is used for treating the liquid rocket fuel, hazardous chemical waste, etc. (Vavruska and Santa $\mathrm{Fe}$ 1997). This invention uses an induction plasma torch for generating steam plasma with temperature greater than $6,000{ }^{\circ} \mathrm{C}$ for conversion of waste products. Water is used for cooling the plasma zone. They used a steam induction plasma torch operating with the steam generated from the device heat loses. It leads to higher overall energy efficiency and higher amount of treated waste for a given electrical power level. Liquid waste material is injected along with dry superheated or saturated atomizing steam into atomizing spray nozzle. After treating with steam plasma torch, waste material is transferred into two reaction chambers at downstream of the steam plasma induction torch for completing the reactions. Steam plasma temperature is significantly lower than that of the argon or other inert gas plasma, which also leads to lower radiation heat loss. Thermal efficiency can be increased by using the heat loss and converting the cooling water to steam and use the steam as a supporting plasma gas. This method provides two purposes: (a) recovering a potentially substantial fraction of plasma heat which normally be lost to a large flow of cooling water and (b) producing dry super-heated steam for plasma gas. As it can be seen in the earlier section, this result also has been used for DC arc water plasma which requires cooled water for electrodes cooling system.

In 1997, a method for treating hazardous or radioactive liquid wastes is investigated (McLaughlin et al. 1997). A non-transferred arc plasma torch is used in this invention for treating wastes. The wastes are mixed with finely divided glass formers (silica, alumina, soda, etc.) and are injected directly into the plasma plume. The plume is in the form of high-velocity jet of superheated gas with a temperature of $5,500{ }^{\circ} \mathrm{C}$. The extremely high temperature inside the plasma and heat transfer between a superheated gas stream and wastes slurry droplets and glass former particles converts the waste to a fully vitrified molten glass product in milliseconds.

Feizollahi and San Ramon (1998) a novel system with a multiple reactor zone is used for treating heterogeneous waste. The system contains a feed subsystem below the plasma torch for providing liquid waste to the reactor. Therefore, the liquid waste is entrained by the plasma jet toward the bed of molten slag material collected at the bottom of the chamber. This invention treats waste material in both oxidation and reduction mode. In oxidation mode, air can be used as the plasma gas. For reduction mode, an inert gas is selected for operation of plasma torch. This invention leads to a complete treatment for different heterogeneous waste.

Using a plasma energy recycle and conversion (PERC) reactor for treatment of waste material is the purpose of the invention of Garrison et al. (1998). This system includes a primary reactor with plasma torch and a secondary reactor to complete the waste treatment process. Argon gas or other suitable gas is converted into a plasma jet by using induction plasma. Depending on the waste material, the atomizing nozzle uses different pressurized gases to spray liquid waste into primary reactor. The intense heat of plasma jet converts the waste material into a gas which goes to the second reactor for complete chemical conversion or destruction of the reactants. Depending on the waste material, the gas product include $\mathrm{CO}_{2}, \mathrm{H}_{2}, \mathrm{~N}_{2}$, and water vapor.

Liquid wastes are treated by plasma torch in 2004 (Gnedenko et al. 2004). The liquid inlet is located near the top of one of the primary plasma torches. The liquid waste is sent directly to a high temperature zone made by one of the plasma torches. This system can be used for liquid wastes which are volatile or organic. These kinds of liquids are volatile in range of $100-500{ }^{\circ} \mathrm{C}$ or in the mid temperature of this range. Therefore, such liquid is converted to gaseous waste before any chemical change by contacting the plasma torch. In this invention, they use two plasma torches in different levels of reactor to convert volatile liquid directly into gaseous product before any vaporization.

An apparatus for treating liquid wastes with a DC and/or AC torch is invented by Capote et al. (2007). The torch flame is adjusted based on the characteristics of the waste. The energy from the torch flame can be used for treating organic waste with a final gasification and dissociation. This apparatus can be used for destroying the hazardous or toxic wastes as well. Nitrogen may be used as the torch gas. This method can process a wide variety of hazardous material to non-hazardous products, acceptable with most of the air and water emission standards. This waste treatment system can produce solid residues in the form of glass which can be recycled or reused without generation of any hazardous bottom ash, fly ash, dioxin, or furan. 
In 2010, Simon developed an effective method for contacting the plasma stream and atomized liquid waste (Simon 2010). This method used an atomizer to produce the jet of small droplets of liquid waste. Liquid enters by atomizer at the opposite of the plasma stream. When the droplets contact the plasma stream (having temperature of about $3,000{ }^{\circ} \mathrm{C}$ ), the waste molecules are dissociated into atoms and/or ions. The ions and atoms move out of the plasma stream and form a mixture of gas products. The plasma torch is a conventional design. It includes watercooling system and two electrodes. The electrical arc is created between these two electrodes.

In another patent, plasma torch energy is applied for inorganic and/or organic liquid waste by a system including processing chamber (Capote et al. 2010). A plurality of plasma torches is used. A nozzle is used to introduce solvent waste to the plasma plume. This nozzle generates atomized micro-droplets solvent. It provides maximum surface area between solvent waste and plasma plume which results in maximum energy transfer. The feeding rate into vessel depends on various factors such as waste characteristics, the energy of heating system versus the required energy for complete gasification of waste, the temperature, and oxygen content in vessel. The residence time varies between $1.75 \mathrm{~s}$ and about $2.00 \mathrm{~s}$. An AC and/or DC plasma torch may be used as an energy source. This system reforms the waste's dissociated molecules to the syngas $\left(\mathrm{CO}\right.$ and $\left.\mathrm{H}_{2}\right)$ comprising elemental components and hydrogen gas.

Most of the above technologies proposed atomizer for introducing liquid into plasma and having well-mixed system. However, among these technologies, only one of them used a different way for making the contact between plasma jet and liquid feed. They submerged the plasma in the volume of liquid and used a draft tube above the torch for the maximum liquid recirculation (Bernier et al. 2001). Moreover, for cooling plasma system, most of technologies used conventional methods. However, two technologies (Dummersdorf et al. 1992; Vavruska and Santa Fe 1997) proposed a novel system for cooling including air and electrode cooling water for steam production.

\section{Summary}

Removing impurities in water and aqueous solution can be achieved by complete oxidation through thermal plasma. Complete oxidation occurs by the interaction of highly active species such as $\mathrm{OH}^{-}$radicals with impurities which form carbon dioxide and water molecules. Plasma activates plasma gas by using high electrical energy. The highly active species can be formed by interaction between the activated gas present in the plasma and the molecules of water vapors. Interaction of highly active species with the components of the liquid phase is possible only if the transfer duration of these species to the gas-liquid interface becomes at least comparable with the recombination and deactivation times of the species (which are very short). Therefore, removing aqueous contaminants by thermal plasma with the oxidation reactions depends on the intensity of mass transfer in the gas phase from the plasma bulk to the interface of gas-liquid. Increasing mass transfer rate can be achieved by creating intense turbulence in the gasliquid system and a decrease in the characteristic size of the gas volume (Samokhin et al. 2010). Therefore, well mixing of plasma jet and solution has a positive influence on the efficiency of the process (Boudesocque et al. 2007). Another important parameter is long residence time of fluid in contact with the high-temperature region, which is required for ensuring complete breakdown of the material. Accordingly, well mixing, high heat and mass transfer between plasma jet and solution has a positive influence on the efficiency of the process. For good mixing and high heat and mass transfer in plasma reactor, high initial turbulence is one approach. Feed introduction method and location, gas flow rate, and reactor size (volume) are the variables of turbulence. Total gas flow rate can be increased by increasing the plasma gas flow rate, introducing a separate gas stream and recycling off-gas back to the reactor. However, increasing gas flow rate decreases the average gas residence time. Also, it causes increasing the heat load on the plasma and the specific energy requirement for processing waste. Decreasing the volume of reactor at a given gas flow rate can increase the turbulence. But the diameter of the reactor should always be larger than the plasma torch gas exit diameter. The location and process of feed introduction can affect turbulence to some extent. The location of feed introduction with respect to the plasma heat source can affect the product quality. The process of feed introduction into reactor is quite important especially for liquid feed. The feed introduction can be (a) radially across the reactor center line, (b) from the bottom of the plasma reactor co-current or countercurrent with the plasma gas, (c) axially, (d) tangentially to create a swirl pattern, (e) by using atomizer or mixing with the plasma gas, and (f) directly inject with plasma gas (in the case of steam plasma).

Fine atomization is the one of the effective methods. Also, improved mixing of reactants with plasma gas and large residence time can be achieved by large recirculation inside the reactor (Snyder et al. 1996). The liquid recirculation in the case of submerged plasma in liquid which leads to enhancement of contact time between plasma gas and liquid phase can also be increased by using a draft tube which is placed above the plasma torch (Fortin et al. 2000). The complete mixing of sample and oxidizing gas can also be reached by transversely introducing sample to plasma 
gas and injecting oxidizing agent at this point. Moreover, mixing liquid waste with oxidizing gas can increase the destruction efficiency. Also, the higher destruction efficiency in thermal oxidation mode can be achieved by using a carrier gas for introducing liquid sample to plasma gas. Liquid sample converts to liquid droplets because of carrier gas. Therefore, the heat transfer from the plasma to sample accelerates due to higher amount of surface to volume ratio for the liquid droplets.

\section{Conclusion}

Thermal plasma treatment can be used for treating waste where landfill is difficult, destruction with incineration requires treatment of the off-gas, emission standard is stringent, and incineration is ineffective. It can be used for treating the waste including waste with a low heating value. It can also be used for liquid hazardous wastes such as PCBs, paint solvents, and cleaning agents. Thermal plasma can be used for producing valuable by-product in waste treatment process. Especially, thermal plasma has potential for treating contaminants in liquid and solution considering the results in the literature.

DC arc processes are chosen for treating the waste with high organics concentration due to having more uniform temperature distribution, arc stability, the availability of reactive species, simple mechanical control requirements, greater bulk gas heating capability, and the facility of performance scale-up. It offers high overall energy efficiency. Real hazardous materials can be treated by DC arc plasma. The $99.99999 \%$ destruction and removal efficiencies (DRE) were achieved for liquid waste containing PCBs and dioxins. Moreover, the emission level of toxic products like dioxin and furan was less well below the strictest environmental standard in the world. But DC arc plasma is dependent on electrode life time. The average life of the electrodes in the oxidative medium is $200-500 \mathrm{~h}$ operation. Therefore, electrode with ability of long-life operation is the major problem for DC plasma, and there is a need for more research to increase its life. Finding a new method like new electrode materials or new plasma gas that can help electrodes lifetime can be an important subject for future research. Finding a DC plasma method for treating the huge amount of liquid waste in a small period of time can also be very useful. Also, as it can be seen in this review, the energy consumption and the destruction and removal efficiencies (DRE) are important factors for waste treatment process. However, they are not mentioned by most of the research works. So, presentation of these parameters is highly recommended for future work. RF plasma offers a smaller and more compact physical structure compared to DC plasma. Also, it can be a good option for treatment of the radioactive waste due to having no consumable parts and no need for part replacement. But, the major problem of the RF plasma process is the low torch efficiency. Therefore, more research is still required for increasing the efficiency of RF torch. The decision for selecting arc plasma or induction plasma system for treatment has to be made by case evaluation and depends on the specific waste stream's form and composition.

Acknowledgments This study was funded by NSERC (Natural Sciences and Engineering Research Council of Canada) discovery grant. We are grateful for the support of NSERC for funding this research.

\section{References}

Armstrong L, Soucy G (2007) Oxidation of Bayer liquor organics with submerged plasma. Light Met 2007:145-149

Bernier JL, Fortin L, Boulos MI, Kasireddy V, Jonquiere C, Soucy G (2001) Thermal plasma reactor and wastewater treatment method. C02F 001/32, US pat 6,187,206

Boudesocque N, Lemort F, Lafon C, Girold C, Meillot E, Vandensteendam C, Baronnet JM (2007) Decontamination and gasification of aqueous organic waste by submerged thermal plasma. 26th annual international conference on incineration and thermal treatment technologies, IT3

Boulos MI, Fauchais P, Pfender E (1994) Thermal plasmas: fundamentals and applications. Plenum Press, New York, pp 1-47

Canadian Council of Ministers of Environment (1992) National guidelines for hazardous waste incineration facilities: design and operating criteria, vol 2. CCME, Toronto, pp 1-33

Capote JA, Menon FK, Rosin JA, Zhou CH (2007) Apparatus for treating liquid waste. F23G 5/10, US pat 7,216,593

Capote JA, Rosin JA, Hsien WU (2010) Method and apparatus of treating waste. F23G 5/10, US pat 7,832,344

Chandler AJ, Associates Ltd. (2006) Review of dioxins and furans from incineration in support of a Canada-wide standard review: a report prepared for: dioxins and furans incineration review group, through a contract associated CCME project\#390-2007

Chang RCW, Vorndran SC, Joseph MF (1989) Method and apparatus for plasma pyrolysis of liquid waste. F23G 5/00, US pat $4,886,001$

Chang K-C, Hsingchu T, Tseng S-T, Huang J-S (1994) Plasma torchjet liquid waste treatment device. F23G 5/00, US pat 5,363,781

Choi S, Watanabe T (2012) Decomposition of 1-decanol emulsion by water thermal plasma jet. IEEE Trans Plasma Sci. doi:10.1109/ TPS.2012.2206059

Deegan AM, Shaik B, Nolan K, Urell K, Oelgemöller M, Tobin J, Morrissey A (2011) Treatment options for wastewater effluent from pharmaceutical companies. Int $J$ Environ Sci Tech 8(3):649-666

Donaldson AD, Apa RP, Eddy TL, Flinn JE (1991) Review of plasma destruction of hazardous mixed waste. 28th National heat transfer conference 161: 41-51

Dummersdorf H, Kunze R, Wohllebe G, Hebecker DL, Noack WG, Dummersdorf HG, Jahn WG, Merten HD (1992) Method for the destruction of toxic waste products and a plasma chemical reactor. B01J 019/08, US pat 5,108,718

Feizollahi F, San Ramon C (1998) Multi-zone waste processing reactor system. B01J 20/34, US pat 5,809,911

Fortin L, Soucy G, Kasireddy VK, Bernier JL (2000) Novel reactor for cyanide solution treatment. Can J Chem Eng 78(4):643-649 
Garrison MM, Edina M, Vavruska JS (1998) Plasma energy recycle and conversion (PERC) reactor and process. F23G 7/00, US pat $5,762,009$

Gnedenko V, Souris A, Pegaz D (2004) Apparatus for processing waste. F23G 5/10, US pat $6,763,772$

Gomez E, Rani DA, Cheeseman CR, Deegan D, Wise M, Boccaccini AR (2009) Thermal plasma technology for the treatment of wastes: a critical review. J Hazard Mater 161(2-3):614-626

Han QY, Heberlein J, Pfender E (1993) Feasibility study of thermal plasma destruction of toxic wastes in a counterflow liquid injection plasma reactor. J Mater Syn Process 1(1):25

Heberlein J, Murphy AB (2008) Thermal plasma waste treatment. J Phys D Appl Phys. doi:10.1088/0022-3727/41/5/053001

Holden HH, Holden HS, Marr Jr, Andrew W (1992) Thermal decomposition of waste material. F23G 5/12, US pat 5,095,828

Huang H, Tang L (2007) Treatment of organic waste using thermal plasma pyrolysis technology. Energy Convers Manag 48(4):1331-1337

Huhn WA, Zwi HR, Lynn A, Dickman R, Wong A, Behr-Andres C, Hemmick E (1997) Radio frequency plasma treatment of organic hazardous waste. Pract Period Hazard Toxic Radioact Waste Manag 1(3):107-112. doi:10.1061/(ASCE)1090-025X(1997)1: $3(107$

Iwao T, Takizawa H, Inaba T, Yumoto M (2005) Heating efficiency of twin torch plasma arc. ISIJ Int 45(8):1084-1087

Knak AN, Kalitko VA, Mosse AL, Fyodorov SA (1997) Plasmathermal processing of toxic halogen-containing organic waste. Int Workshop Electr Arc Plasma Technol Process 70(4):593-597

Kong P (2006) Atmospheric-pressure plasma process and applications. Sohn international symposium on advanced processing of metals and materials. In: Proceeding of international symposium on new, improved and existing technologies aqueous electrochemical process 493-506

Kulkarni P (1990) Method and apparatus for treatment of hazardous waste in absence of oxygen. F23G 7/04, US pat 4896614

Langmuir I (1928) Oscillations in ionized gases. Proc Natl Acad Sci USA 14(8):627-637

Mabrouk M, Lemont F, Baronnet JM (2012) Incineration of radioactive organic liquid wastes by underwater thermal plasma. 12th high tech plasma processes conference. doi:10.1088/17426596/406/1/012002

Maehara T, Toyota H, Kuramoto M, Iwamae A, Tadokoro A, Mukasa S, Nomura S, Yamashita H, Kawashima A, Nomura S (2006) Radio frequency plasma in water. Jpn J Appl Phys Part 1 45(11):8864-8868

Maehara T, Miyamoto I, Kurokawa K, Hashimoto Y, Iwamae A, Kuramoto M, Yamashita H, Mukasa S, Toyota H, Nomura S, Kawashima A (2008) Degradation of methylene blue by RF plasma in water. Plasma Chem Plasma Process 28(4):467-482. doi:10.1007/s11090-008-9142-2

Maehara T, Nishiyama K, Onishi S, Mukas S, Toyota H, Kuramoto M, Nomura S, Kawashima A (2010) Degradation of methylene blue by radio frequency plasmas in water under ultraviolet irradiation. J Hazard Mater 174(1-3):473-476. doi:10.1016/j. jhazmat.2009.09.07

Magureanu M, Piroi D, Mandache NB, David V, Medvedovici A, Parvulescu VI (2010) Degradation of pharmaceutical compound pentoxifylline in water by non-thermal plasma treatment. Water Res 44(11):3445-3453. doi:10.1016/j.watres.2010.03.020

Malakootian M, Yousefi N, Fatehizadeh A (2011) Survey efficiency of electrocoagulation on nitrate removal from aqueous solution. Int J Environ Sci Tech 8(1):107-114

Malik MA, Ubaid-ur-Rehman, Ghaffar A, Ahmed K (2002) Synergistic effect of pulsed corona discharges and ozonation on decolourization of methylene blue in water. Plasma Sources Sci Technol 11(3):236-240. doi:10.1088/0963-0252/11/3/302
McLaughlin DF, Dighe SV, Gass WR (1997) Plasma vitrification of waste materials. C03B 5/16, US pat 5,637,127

Moody JR, George AP, Peeling RH, Jones SM (1993) Destruction process. H05B 7, US pat 5,206,879

Moustakas K, Fatta D, Malamis S, Haralambous K, Loizidou M (2005) Demonstration plasma gasification/vitrification system for effective hazardous waste treatment. J Hazard Mater 123(1-3):120-126. doi:10.1016/j.jhazmat.2005.03.038

Munholand L, Quintal P, Soucy G (2006) A hydrodynamic study of a plasma lift reactor. Can J Chem Eng 84(1):73-82

Murphy AB (1999) Plasma destruction of gaseous and liquid wastes. Ann N Y Acad Sci 891:106-123. doi:10.1111/j.1749-6632.1999. tb08758.x

Narengerile, Watanabe T (2012) Acetone decomposition by water plasmas at atmospheric pressure. Chem Eng Sci 69(1):296-303. doi:10.1016/j.ces.2011.10.045

Narengerile, Yuan M, Watanabe T (2011) Decomposition mechanism of phenol in water plasmas by DC discharge at atmospheric pressure. Chem Eng J 168(3):985-993. doi:10.1016/j.cej.2011.01.072

Nishioka H, Saito H, Watanabe T (2009) Decomposition mechanism of organic compounds by DC water plasmas at atmospheric pressure. Thin Solid Films 518(3):924-928

Onundi YB, Mamun AA, Al Khatib MF, AlSaadi MA, Suleyman AM (2011) Heavy metals removal from synthetic wastewater by a novel nano-size composite adsorbent. Int $\mathbf{J}$ Environ Sci Tech 8(4):799-806

Pacheco JO, Ramos F, Cruz A, Garcia MA, Benitez JS, Lopez R (2001) Recovering energetic gas from hydrocarbon solutions treated by thermal plasma. In: Proceedings of 25th international conference on phenomena in ionized gases 4:135-136

Pfender E (1999) Thermal plasma technology: where do we stand and where are we going? Plasma Chem Plasma Process 19(1):1-31. doi:10.1023/A:1021899731587

Samokhin AV, Alekseev NV, Lainer YA, Tsvetkov YV (2010) Oxidation of organic impurities in production aluminate solutions under the effect of the thermal plasma jet. Russ $\mathbf{J}$ Non Ferrous Met 51(3):217-221

Seok-Wan K, Hyun-Seo P, Hyung-Jin K (2003) 100 kW steam plasma process for treatment of PCBs (polychlorinated biphenyls) waste. Vacuum 70(1):59-66

Simon YY (2010) Method and system for treating chemical waste. F23G 5/10, US pat 7,677,185

Smith RW, Mutharasan R, Knight R, Malladi K (1995) Inductioncoupled plasma energy recycle and conversion (PERC) of military waste streams. 12th International symposium on plasma chemistry 1057-1063

Snyder HR, Fleddermann CB (1997) Decomposition of dichloroethane in a plasma arcjet reactor: experiment and modeling. IEEE Int Conf Plasma Sci 1997:312-313

Snyder HR, Fleddermann CB, Gahl JM (1996) Destruction of acetone using a small-scale arc jet plasma torch. Waste Manag 16(4):289-294

Soucy G, Bergeron É, Boulos MI (1998) Design of an induction plasma reactor for the reforming of aromatic liquid wastes. High Temp Mater Process 2(2):195-206

Soucy G, Poirier G, Quintal P, Andrejack M (2006) Organic destruction in synthetic Bayer liqour by submerged thermal plasma. 17th International symposium on ICSOBA combined with light metals 33:280-290

Tomizawa S, Tezuka M (2006) Oxidative degradation of aqueous cresols induced by gaseous plasma with contact glow discharge electrolysis. Plasma Chem Plasma Process 26(1):43-52. doi:10. 1007/s11090-005-8724-5

Vavruska JS, Santa Fe NM (1997) Induction steam plasma torch for generating a steam plasma for treating a feed slurry. B23K $10 / 00$, US pat $5,611,947$ 
Yargeau V, Soucy G, Boulos MI (1999) The treatment of water-based toxic waste using induction plasma technology. Plasma Chem Plasma Process 19(3):327-340

Yargeau V, Soucy G, Marcos B (2001) Black liqour treatment by thermal plasma. 15th International symposium on plasma chemistry 7:2987-2991
Yargeau V, Marcos B, Soucy G (2004) A new application of the severity factor kinetic model: thermal plasma treatment of black liquor. Can J Chem Eng 82(6):1209-1216

Yuan M, Narengerile WatanabeT, Chang C (2010) DC water plasma at atmospheric pressure for the treatment of aqueous phenol. Environ Sci Technol 44(12):4710-4715 